\title{
Geophysical Investigations of the Mound City Borrow Pits, Ross County, Ohio
}

\author{
by \\ Blair Elizabeth Benson \\ B.S., James Madison University, 2009
}

Submitted to the Department of Geology and the Faculty of the Graduate School of the University of Kansas in partial fulfillment of the requirements for the degree of Master of Science

George Tsoflias, Co-Chairman

Rolfe Mandel, Co-Chairman

Ross Black, Committee Member

Date Defended: 
The Thesis Committee for Blair Benson certifies

That this is the approved version of the following thesis:

Geophysical Investigations of the Mound City Borrow Pits, Ross County, Ohio

Committee:

Co-Chairman

Co-Chairman

Committee Member

Date Approved: 


\section{ABSTRACT}

Geophysical subsurface imaging is becoming a common practice in archaeology. Non-invasive geophysical methods provide efficient alternatives to costly and invasive excavations, allowing archaeologists to analyze sites before any excavation is done to identify areas of interest. For my thesis, I investigated two prehistoric borrow pits at the Mound City Group (200 BC - 200 AD) in the Hopewell Culture National Historical Park in south-central Ohio. The primary objective of this study was to determine the presence and spatial extent of a clay lining that was emplaced upon the borrow pits by the Hopewell people. Information gleaned from the geophysical investigation was used to assess the degree of site disturbance from agriculture, construction of Camp Sherman, and modern reconstruction of the earthworks.

My analysis included a suite of overlapping geophysical surveys consisting of ground-penetrating radar, magnetometry, electromagnetic induction, and electrical resistivity. The geophysical data was ground-truthed with limited auguring and trenching. Analysis of the first borrow pit data showed strong evidence of historical disturbance within the pit from construction of Camp Sherman, including disturbed soil and a buried utility pipe, leaving little of the clay lining present except around the edges of the borrow pit. The geophysical data for the second borrow pit showed less historical damage that was primarily caused from the re-excavation of the pit during the reconstruction of the park. The second borrow pit still retains about half of the clay lining, a finding supported by the results of auguring and trenching. These results are evidence that the borrow pits at Mound City may have also served a purpose as cultural landscape features. The geophysical methods used in this study proved to be an invaluable source of information with minimal disturbance of the site. 


\section{Acknowledgements}

First off, I would like to begin by thanking Nick, my soon to be husband, for all of his support these past few years. He has never once grumbled about my busy, erratic schedule, but only did whatever he could to help, and for that I am so grateful. My advisors George Tsoflias and Rolfe Mandel, who teamed up to work with me and helped me create a project that I am truly proud of. They have both always encouraged me and pointed me in the right direction and I couldn't have accomplished this without them. I would like to thank Ross Black for being on my committee and always being around when I had a question or needed feedback. Everyone at the Midwest Archeological Center, particularly Mark Lynott, Steve De Vore, and Ann Bauermeister, for allowing me to work with them, use their equipment, and most importantly allow me the opportunity to work at such an interesting research site! Huge thanks to all of the KU students who have provided their feedback and helped when I got stuck: Brian Miller, Anthony Hoch, Jose Velez, Matt Baker, Kwanyee Cheng, and Brooke Perini. My parents for their constant excitement and enthusiasm in hearing about what I am doing. Finally, I would like to say a very special thank you to Don Steeples for his amazing support, guidance, and advice. Stopping by his office in the mornings to say hello and chat was always a great start to the day. 


\section{Table of Contents}

$\begin{array}{ll}\text { I. Introduction } & 1\end{array}$

$\begin{array}{ll}\text { II. Site Background } & 5\end{array}$

A. Geologic Setting 5

B. Previous Research 5

$\begin{array}{ll}\text { III. Methodology } & 10\end{array}$

A. Geophysical Methods 12

B. Data Processing 23

C. Trenching and Auguring 26

$\begin{array}{lr}\text { IV. Results } & 29\end{array}$

A. BP1 Geophysical Results 29

B. BP2 Geophysical Results 35

C. Test Trenches and Augers 43

$\begin{array}{ll}\text { V. Discussion } & 50\end{array}$

$\begin{array}{ll}\text { VI. Conclusions } & 53\end{array}$

$\begin{array}{ll}\text { VII. References } & 54\end{array}$

$\begin{array}{ll}\text { VIII. Appendix A } & 57\end{array}$ 


\section{List of Figures and Tables}

Figure 1 Regional Map 2

$\begin{array}{lll}\text { Figure } 2 & 1848 \text { Squire and Davis Map } & 8\end{array}$

$\begin{array}{lll}\text { Figure } 3 & \text { Modern Map of the site } & 12\end{array}$

$\begin{array}{lll}\text { Figure } 4 \quad \text { Sample GPR line } & 15\end{array}$

$\begin{array}{lll}\text { Figure } 5 & \text { Total Intensity Map of the Geomagnetic Field } & 17\end{array}$

$\begin{array}{lll}\text { Figure } 6 & \text { Sample Magnetic Line } & 18\end{array}$

Figure $7 \quad$ Typical Resistivity Ranges in Rocks and Soils $\quad 20$

Figure 8 Dipole-Dipole Electrical Resistivity Survey Array 20

$\begin{array}{lll}\text { Figure } 9 & \text { Sample Resistance Line } & 21\end{array}$

Figure $10 \quad$ Sample Conductivity Line 23

Figure 11 Contour Map of the Survey Grid of BP1 27

Figure 12 Contour Map of the Survey Grid of BP2 28

$\begin{array}{lll}\text { Figure } 13 & \text { BP1 Magnetic Data } & 31\end{array}$

Figure 14 BP1 Conductivity and Resistance Data 32

Figure $15 \quad$ GPR Time Slice and Cross Section from BP1 33

Figure $16 \quad$ GPR Cross Section Panel from BP1 34

$\begin{array}{lll}\text { Figure } 17 & \text { BP2 Magnetic Data } & 38\end{array}$

Figure 18 BP2 Conductivity and Resistance Data 39

Figure 19 GPR Survey Line from BP2 and Corresponding Resistance Line $\quad 40$

Figure 20 GPR Survey Line from BP2 and Corresponding Resistance Line $\quad 41$

Figure $21 \quad$ GPR Time Slice Panel from BP2 42

Figure 22 North Wall Cross Section of Test Trench in BP1 46 
Figure 23 West Wall Cross Section of Test Trench in BP2

Figure $24 \quad$ Integrated Soil Auger Map of BP1

Figure 25 Integrated Soil Auger Map of BP2

Figure 26 BP2 Clay Map

Table 1 Geophysical Survey Acquisition Parameters

Table 2 GPR Material Properties

Table 3 GPR Data Processing Steps

Table $4 \quad$ Soil Description of Trench Units 


\section{Introduction}

Geophysical surveying is emerging as a useful method in archeology; it is an efficient, non-invasive means of surveying potential cultural sites. This is important because new legislation affecting modern archeology prevents standard excavation techniques, especially at prehistoric sites. These standard excavation techniques are destructive to sacred cultural patrimony at Native American burial mounds and ceremonial centers (Whittaker \& Storey, 2008). With the aid of geophysical subsurface imaging techniques, archeologists can identify sensitive areas, such as those containing cultural remains, and avoid disturbing them (Conyers, 2004).

For my thesis, I used multiple geophysical subsurface imaging methods, including ground-penetrating radar (GPR), magnetometry, electrical resistivity, and electromagnetic induction (conductivity), to investigate prehistoric earthworks in south-central Ohio. These geophysical methods were ground-truthed with soil augers, the locations of which were selected from the interpretation of the geophysical data. Specifically, I surveyed two of the eight borrow pits at the Mound City site, located in Ross County, Ohio (Figure 1).

Mound City is a prehistoric ceremonial center composed of burial mounds enclosed within a large square embankment and surrounded by eight borrows pits. The term borrow pit is used to describe an area where material has been excavated for construction at another location. Mound City was constructed by a group of indigenous people, the Hopewell, during the Middle Woodland period (200 BC - 200 AD). The goal of this research was to determine if agriculture, construction of Camp Sherman, and modern reconstruction of the earthworks have affected the integrity of these pits, specifically a clay lining that was 
emplaced atop the borrow pits by the Hopewell. I also identified the geophysical methods that were most effective.



Figure 1: Regional Map of the Mound City Group located in south-central Ohio (Modified from http://www.iptv.org/bestofthemidwest/mappopup_midwest.cfm and Google Earth). The circles seen within the embankment in the zoomed in image to the right are the mounds.

Several successful investigations have been published that use one or a combination of geophysical subsurface imaging techniques at archeological sites to identify features of interest in the subsurface as well as features of interest. Stierman and Brady (1999) used electrical resistivity to identify natural subsoil below prehistoric earthworks, and to recognize imported fill brought in to level out the adjacent low-lying landscape in Honduras. Resistivity methods employed at the Sprunk site in North Dakota revealed the remnants of circular house structures, which most likely represent areas of temporary 
occupation (Lowe and Fogel, 2010). This finding contradicted the notion that square houses existed in the area, which usually implies more permanent occupation.

Magnetic surveys completed in the Missouri River Basin of North and South Dakota proved extremely useful at locating house floors, postholes, hearths, storage pit features, and middens (trash piles) at both prehistoric and historic sites (Kvamme, 2003). De Vore (2010) completed a large-scale magnetic survey of the interior of the embankment walls at the Mound City Group and discovered a vast amount of archeological resources and features, including possible mounds that are no longer visible at the surface, prehistoric structures, activity areas, and disturbances from recent occupations of the site.

Conductivity surveys are especially useful for identifying boundaries between stratigraphic units such as clay and gravel, which can lead to a more accurate interpretation of where archaeological materials can be found (Conyers, et al. 2008). These surveys also are often used to detect buried pipes and utility lines.

Ground-penetrating radar (GPR) was used at Effigy Mounds National Monument, a prehistoric earthworks in northeastern Iowa, where it allowed researchers to define separate strata within the mounds, and to identify disturbed soil and potential archeological features (Whittaker and Storey, 2008). GPR was also used successfully in imaging depressions thought to contain prehistoric Chaco ceremonial centers at a site in Utah. Data from the GPR revealed several small kivas and building remnants, indicating that the site contained small family settlements instead of the previously hypothesized Great Kivas (Conyers and Osburn, 2006).

Prior to my study, several questions remained unanswered about the Mound City borrow pits. For example, was this clay lining present in all of the borrow pits surrounding 
the site, did it extend across the entire length of the borrow pit, what was the purpose of emplacing this clay lining and how much of the clay lining still remains at the site today. I chose to answer these questions using nondestructive techniques. Specifically, four geophysical surveying methods were employed at two of the borrow pits. The results of these surveys were verified with subsurface data gleaned from hand auguring that caused minimal disturbance. 


\section{Site Description}

\section{A. Geologic and Geomorphologic Setting}

Bedrock in the area of Mound City consists of Devonian-aged sedimentary units, including the Ohio Shale and the Berea Sandstone (Thornberry-Ehrlich, 2010). Thick till deposits that aggraded during the Wisconsin Glacial Episode (ca. 110,000-10,000 years ago) mantle the uplands surrounding Mound City.

Mound City was constructed on a high, Pleistocene terrace of the Scioto River. The terrace fill consists of sand and gravel capped by a thin veneer of fine-grained alluvium. The Scioto River is the second largest river in Ohio and floods on an annual basis (Hardin, et al., 1989). In the 1980 's, riprap was installed to protect the site from flooding of the Scioto River, and trees were planted along the riverbank to help prevent erosion of the site. The river has since migrated away from the problem area (Thornberry-Ehrlich, 2010).

\section{B. Previous Archeological Research}

Mound City consists of 24 mounds surrounded by an earthen embankment that encloses approximately 15 acres (Brown, 2004). The earthworks were originally constructed between $200 \mathrm{BC}$ and $200 \mathrm{AD}$ by the Hopewell, an indigenous group of Native Americans. These people were not a single unified society, but instead formed a network of Middle Woodland societies that designed and built some of the largest indigenous earthen architecture in the country and manufactured artifacts from imported materials (Abrams, 2009). Hopewell sites occur across the Midwest and eastern United States, but the largest clusters of sites are within the Scioto River valley of south-central Ohio. 
In 1848, Mound City was recorded and mapped by Ephraim Squire and Edwin Davis (Squier and Davis, 1848). William C. Mills excavated some of the mounds in the 1920's (Mills, 1922), and James Brown led a series of investigations in the 1960's to further examine the submound features, relocate and reconstruct the southeast embankment wall, and relocate and reconstruct several of the mounds (Brown, 1994). The majority of this prior research has focused on the mounds and the embankment walls, addressing how they were constructed, what they were used for, and the source of the construction material. Less attention has been directed towards the borrow pits at the site.

Squier and Davis originally recorded seven pits outside the embankment wall (Figure 2). They believed that these features were created when earth material was removed and used as fill for the mounds inside the embankment walls. In 1963, Brown discovered an eighth pit in the southeast corner of the site, adjacent to the embankment wall. This discovery led to the interpretation that the pits may have a symmetrical arrangement, with one pit at each of the corners and a pit on either side of the gateways along the embankment walls (Brown, 1994).

During the early 1900's, soil and sediment were used to fill many of the borrow pits in order to level the landscape for agriculture and the construction of Camp Sherman, a WWI training camp built during the summer of 1917. Camp Sherman was the third largest military training facility in the nation during that time, with over 120,000 soldiers trained and over 1,300 buildings, a railroad system, and its own utility lines (Ohio Historical Society, 2005). When the war ended, the site was used as a temporary hospital and trade school for the veterans until the 1920s when it was officially closed and dismantled. President Warren G. Harding designated Mound City as a National Monument in 1923, and 
the property was turned over to the State of Ohio. Restoration and preservation of Mound City began in 1925 (De Vore, 2010).

It is unclear which borrow pits were filled and leveled during the Camp Sherman occupation. Henry C. Shetrone, the curator of archeology for the Ohio Historical Society during that time, was able to persuade the commander of Camp Sherman to leave Mound 7 and some of the borrow pits beside it untouched, but there are no records indicating which borrow pits were preserved (Brown, 1994). In the 1960's, the Ohio Historical Society and National Park Service re-excavated the leveled borrow pits, using Squire and Davis's 1848 map to locate them. The pits were restored without acknowledging their original size based on Squire and Davis's records (Hanson, 1966).

Archeological excavations during the 1960's revealed prehistoric artifacts such as pottery, mica, bladelets, and projectile points in the southeast borrow pit. Also, burials were uncovered in the southeast and northwest borrow pits (Brown and Baby, 1966). Based on radiocarbon ages, Brown (1994) concluded that the Mound City Group was constructed during the Middle Woodland period. The borrow pits appear to have been excavated during the second phase of occupation (AD 1-200) after the construction of the majority of the mounds and in conjunction with the erection of the embankment wall.

Based on the results of recent investigations at Mound City, the borrow pits may have been used for multiple purposes. Lynott et al. (2010) noted that it is unusual for borrow pits to occur in such close proximity to enclosure walls at prehistoric earthworks in the Scioto River Valley. In 2009, Mark Lynott of the Midwest Archeological Center (MWAC) conducted a preliminary study of the borrow pits at Mound City. His investigation resulted 


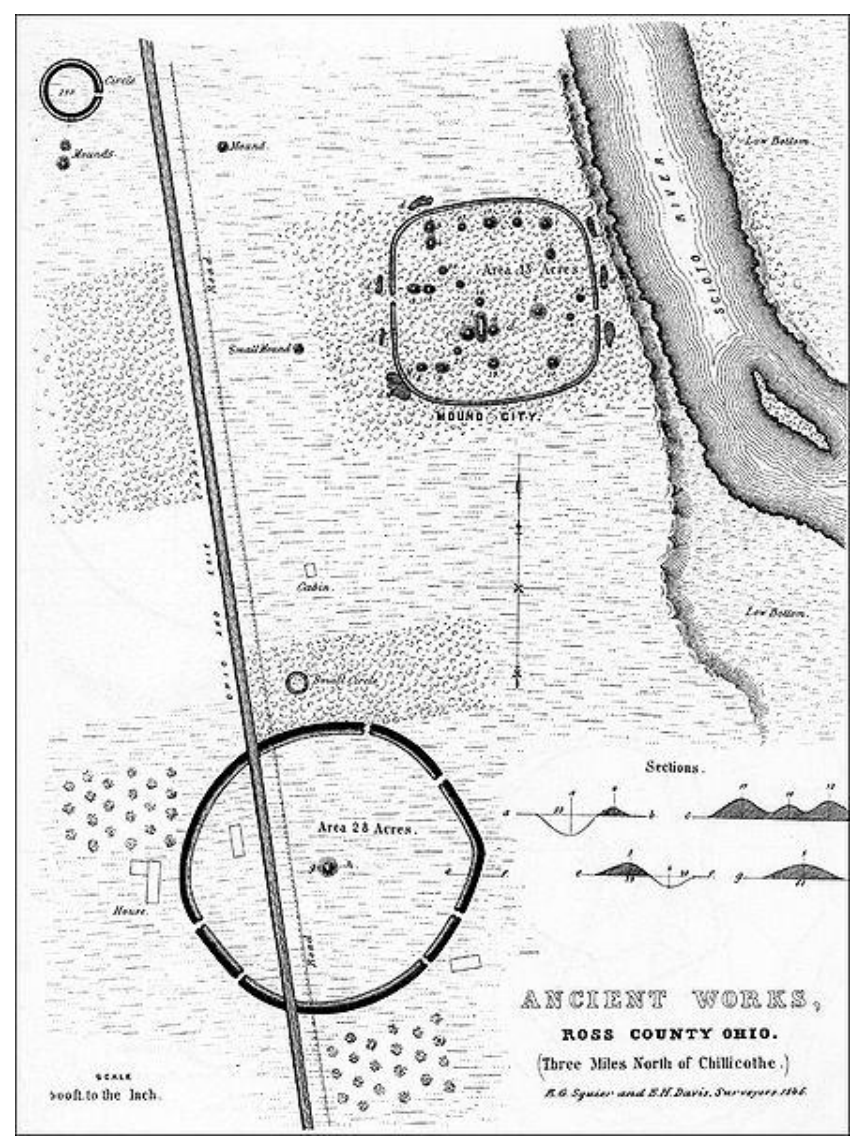

Figure 2: 1848 Squire and Davis map of Mound City. Reproduced in De Vore (2010).

in the discovery of a thin layer of clay overlying sand and gravel in the southeast borrow pit (BP1). In 2010, a clay layer also was found in the east borrow pit (BP2), north of the east gate entrance. These clay layers are not natural features; they do not fine upward, which is indicative of flood deposits, and they have a random distribution. It appears that the clay was emplaced by the Hopewell during the construction of the borrow pits. If these borrow pits were simply being used as quarry sites for the mound fill, then it seems unlikely that the builders would have gone to the trouble of emplacing a clay liner to stabilize them (Lynott, et al., 2010). This evidence, along with the many artifacts and burials that have been found, suggests that the borrow pits at Mound City may have also served as cultural landscape features designed by the Hopewell. 
Most recently, Burks and Cook (2011) completed a large-scale magnetic survey of three Hopewell earthworks also located in south-central Ohio. At one of their sites, known as the Shriver Circle, two trenches were dug into a ditch positioned along the northern side of the enclosure. They found in the second trench a prehistoric clay liner that had been emplaced above the unconsolidated terrace gravels. This is a significant discovery indicating that emplacement of a clay liner was not unique to Mound City, and that clay liners may occur at Hopewell sites throughout the Scioto River Valley. 


\section{Methodology}

Two of the eight borrow pits, BP1 and BP2, were selected for detailed study (Figure 3). In 2009, Steve Devore of MWAC conducted a geophysical survey at BP1. In June of 2010 I collected geophysical data at BP2, a project supported by MWAC. Four types of geophysical survey methods were used in this investigation, including ground-penetrating radar, magnetometry, electrical resistivity, and electromagnetic induction (conductivity). The individual instruments survey parameters are presented in Table 1. MWAC owns the geophysical instruments used for this research. The grids for BP1 and BP2 were established by MWAC in 2009 and 2010, respectively. BP1 covered a total area of $800 \mathrm{~m}^{2}$, and BP2 covered a total area of $640 \mathrm{~m}^{2}$. Both grids were set up using the Ushikata surveying compass. 


\begin{tabular}{|c|c|c|c|}
\hline Instrumentation & Line Spacing & Sampling Interval & Notes \\
\hline $\begin{array}{c}\text { GSSI SIR 3000 } \\
\text { Ground- } \\
\text { Penetrating Radar }\end{array}$ & $0.5 \mathrm{~m}$ & $\begin{array}{c}0.02 \mathrm{~m} \text { trace } \\
\text { spacing with } 0.17 \\
\text { ns sampling } \\
\text { interval }\end{array}$ & $400 \mathrm{MHz}$ antennas \\
\hline $\begin{array}{c}\text { FM256 Single } \\
\text { Fluxgate } \\
\text { Gradiometer } \\
\begin{array}{c}\text { RM15 Resistance } \\
\text { Meter }\end{array}\end{array}$ & $0.5 \mathrm{~m}$ & $0.125 \mathrm{~m}$ & $\begin{array}{c}0.5 \mathrm{~m} \text { sensor } \\
\text { separation }\end{array}$ \\
\hline $\begin{array}{c}\text { EM38 Conductivity } \\
\text { Meter }\end{array}$ & $0.5 \mathrm{~m}$ & $0.5 \mathrm{~m}$ & $\begin{array}{c}\text { Dipole-Dipole } \\
\text { Array with } 40 \mathrm{~V} \\
\text { output }\end{array}$ \\
\hline $\begin{array}{c}\text { Bartington Grad } \\
601 \text { Dual Fluxgate } \\
\text { Gradiometer }\end{array}$ & $1 \mathrm{~m}$ & $0.25 \mathrm{~m}$ & $\begin{array}{c}\text { Frequency of } 14.6 \\
\text { KHz }\end{array}$ \\
\hline
\end{tabular}

Table 1: Geophysical Survey Acquisition Parameters 




Figure 3: Modern map of the Mound City Group site identifying the location of the two borrow pits investigated (BP1 and BP2). The red circle indicates the assumed position of the northeast borrow pit (Lynott and Monk, 1985).

\section{A. Geophysical Survey Methods}

Ground-Penetrating Radar

Ground-penetrating radar is an active method that transmits a short pulse of high frequency electromagnetic energy, usually in the range of $10-1000 \mathrm{MHz}$, into the ground by an antenna. Changes in the electrical properties of the ground create interfaces that reflect back part of the transmitted signal, which is detected by the receiving antenna and stored for data processing and display (Davis and Annan, 1989). The electrical properties of the material in the ground (i.e. the dielectric constant and the electrical conductivity) determine the radar signal velocity, the attenuation, and the power that is reflected back 
from interfaces to the receiving antenna (Davis and Annan, 1989). Table 2 shows a list of common geological materials with their dielectric constant, EM wave velocity of propagation, electrical conductivity, and attenuation at a radar frequency of $100 \mathrm{MHz}$.

One of the most important considerations when using ground-penetrating radar at any site is assessing image resolution and depth of penetration. Resolution is the ability of the system to distinguish two signals that are close to each other in time (Davis and Annan, 1989). Higher frequencies offer finer resolution, which allows the detection of small artifacts, such as the ones found at archeological sites. Resolution is approximately one quarter of the signal wavelength, which is a function of the velocity of propagation and the frequency of the signal, i.e.

$$
\lambda=v / f
$$

where $\lambda$ is the wavelength of the signal, $v$ is the velocity of propagation, and $f$ is the dominant frequency. Radar depth penetration is largely affected by signal attenuation, which is the decrease in intensity of a wave as a result of absorption of energy and scattering (Burger, et al., 2006). Attenuation occurs more in high electrical conductivity, fine-grained materials like clay, silts, and shales, and increases with higher frequencies (see Table 2). This can create a problem for very shallow archeological sites that require higher frequency sources. Attenuation for a low-loss medium can be calculated using equation 2,

$$
\alpha=\frac{1.69 \times 10^{3} \sigma}{\mathrm{K}^{1 / 2}}
$$

where $\alpha$ is the attenuation, $\sigma$ is the electrical conductivity, and $\mathrm{K}$ is the dielectric constant.

The first use of GPR in an archeological investigation was in 1975 at Chaco Canyon, NM, where it was employed to investigate potential buried walls (Conyers and Goodman, 
1997). Since then, the application of two and three dimensional visualization processes has increased the amount of valuable reflection data that can be used in archeological studies. Also, GPR systems have become very portable. Complete systems, which usually consist of surface antennas, a radar system to produce pulses, a computer to process and save the data, a video monitor, a keyboard, and a power source, can be transported into remote areas in a backpack (Johnson, 2006). Processing can then be completed in the field just minutes after acquiring the data, allowing archeologists to immediately target areas for excavation (Conyers, 2004).

Ground-penetrating radar was used at Mound City to image the stratigraphy of the two borrow pits, as well as identify where any anomalies, such as buried artifacts or features, may occur. The GSSI SIR 3000 ground-penetrating radar was used with the 400 $\mathrm{MHz}$ antenna. Data were collected at a trace spacing of $2 \mathrm{~cm}$ and 512 samples per trace with a line spacing of $0.5 \mathrm{~m}$. Figure 4 shows a sample GPR profile from BP1. Data were recorded to a depth of $4.23 \mathrm{~m}$ with an approximate vertical resolution of $5.6 \mathrm{~cm}$. The depth of interest for this study is the top $1 \mathrm{~m}$. 


\begin{tabular}{|c|c|c|c|c|}
\hline Material & $\mathbf{K}$ & $\boldsymbol{\sigma} \mathbf{( m S / m )}$ & $\mathbf{V} \mathbf{( m / n s )}$ & $\boldsymbol{\alpha} \mathbf{( d B} / \mathbf{m})$ \\
\hline Air & 1 & 0 & 0.30 & 0 \\
\hline Distilled Water & 80 & 0.01 & 0.033 & $2 \times 10^{-3}$ \\
\hline Fresh Water & 80 & 0.5 & 0.033 & 0.1 \\
\hline Sea Water & 80 & $3 \times 10^{4}$ & 0.01 & $10^{3}$ \\
\hline Dry Sand & $3-5$ & 0.01 & 0.15 & 0.01 \\
\hline Saturated Sand & $20-30$ & $0.1-1.0$ & 0.06 & $0.03-0.3$ \\
\hline Limestone & $4-8$ & $0.5-2$ & 0.12 & $0.4-1$ \\
\hline Shales & $5-15$ & $1-100$ & 0.09 & $1-100$ \\
\hline Silts & $5-30$ & $1-100$ & 0.07 & $1-100$ \\
\hline Clays & $5-40$ & $2-1000$ & 0.06 & $1-300$ \\
\hline Granite & $4-6$ & $0.01-1$ & 0.13 & $0.01-1$ \\
\hline Dry salt & $5-6$ & $0.01-1$ & 0.13 & $0.01-1$ \\
\hline Ice & $3-4$ & 0.01 & 0.16 & 0.01 \\
\hline
\end{tabular}

Table 2: GPR Material Properties. Dielectric constant (K), electrical conductivity $(\sigma)$, velocity $(\mathrm{V})$, and attenuation $(\alpha)$ of geologic materials at a frequency of $100 \mathrm{MHz}$ (Davis and Annan, 1989).

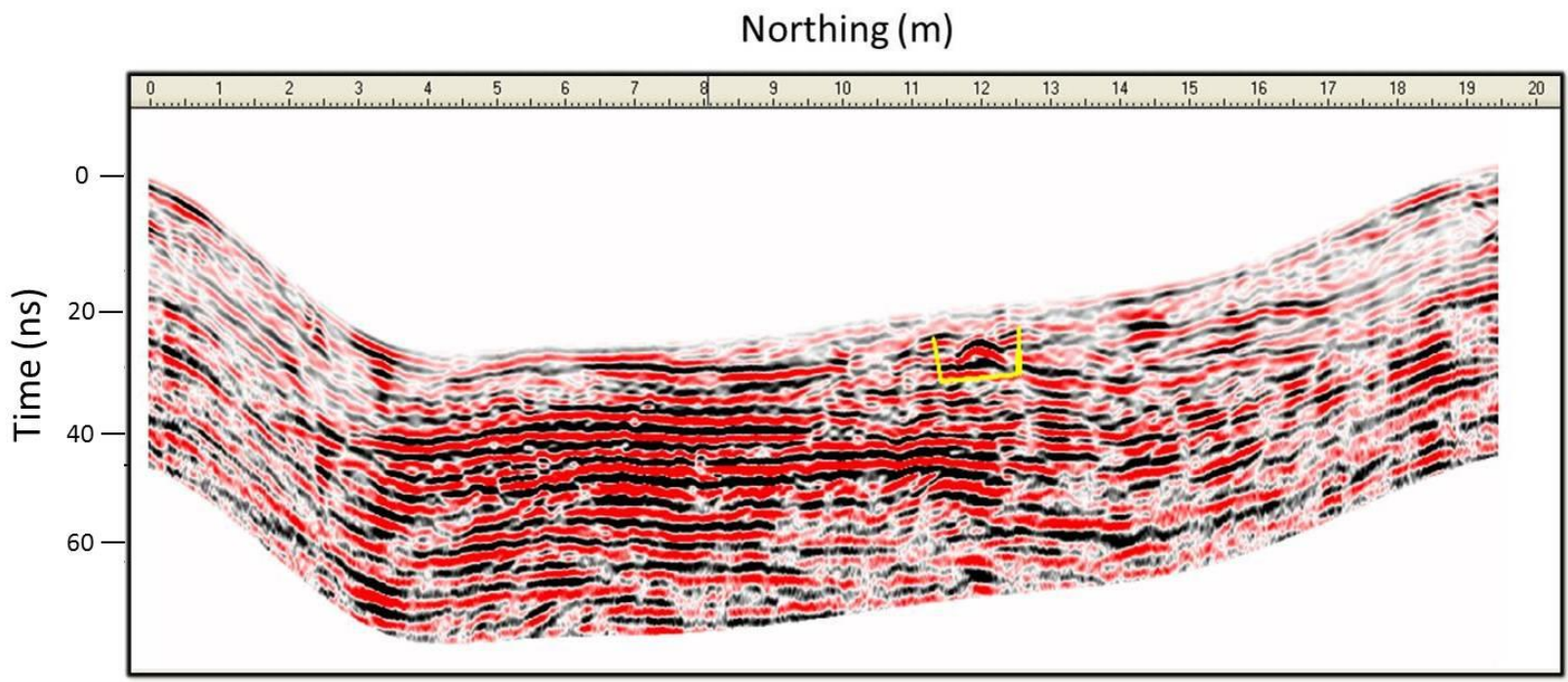

Figure 4: Sample GPR line from BP1 at 896.5 meters east, oriented south (left) to north (right). The red colors correspond to negative amplitude values and the black colors correspond to positive amplitude values. The hyperbolic shaped anomaly (diffraction) in the yellow box represents a buried utility pipe. Twenty nanoseconds two-way travel time corresponds to approximately $1 \mathrm{~m}$ in depth. Surface topography is incorporated in the profile. 


\section{Magnetometry}

Magnetic surveys are passive methods that measure the magnitude of the earth's magnetic field (in nanoteslas) at a single point. The earth's magnetic field ranges from about 30,000 $\mathrm{nT}$ at the magnetic equator to about 60,000 $\mathrm{nT}$ at the magnetic poles (Figure 5) (Butler, et al., 2006). Magnetic surveys can be conducted using several types of magnetometers, including fluxgate, proton-precession, or alkali-vapor (Ward, 1990). A fluxgate gradiometer was used in my study. These magnetometers consist of two magnetic sensors that are separated by a fixed distance, with measurements recorded simultaneously in both sensors. The difference of the Earth's magnetic field measured between the two sensors provides a measure of the magnetic gradient. Gradiometers are especially useful because they minimize regional anomalies, increase resolution, and eliminate temporal magnetic field variations (Ward, 1990). In addition, they are capable of recording both the horizontal and vertical components of the magnetic field, which gives the user directional information as well (Burger, et. al., 2006).

Magnetic surveys have served a very important role in archeological studies. The high susceptibility of iron objects associated with some sites and the strong thermoremanent magnetism produced during manufacture of bricks, tiles, pottery, and kilns and hearth use make magnetic surveys extremely useful in locating buried sites (Burger, et. al, 2006). Positive magnetic anomalies are associated with features such as fire pits, kilns, and the foundations of historic buildings. Negative magnetic anomalies are usually associated with graves, middens, wells, and prehistoric structures (Rapp and Hill, 2006). Based on previous research, magnetic anomalies of archeological interest often measure $+/-5 \mathrm{nT}$ relative to the background magnetic field, and different soil horizons can 
have as subtle as a $0.5 \mathrm{nT}$ change (Johnson, 2006). Most importantly, magnetic surveys are quick and efficient, and can cover a large area in a small amount of time.

For this research, magnetic surveys were used to identify potential historic features that have disturbed the original integrity of the site, as well as potential prehistoric features such as hearths. Two different magnetometers were used. The first was the FM256 Single Fluxgate Gradiometer with a probe separation of $0.5 \mathrm{~m}$. The line spacing was set at $0.5 \mathrm{~m}$ with a sampling interval of $0.125 \mathrm{~m}$. The second instrument used was the Bartington Grad 601 Dual Fluxgate Gradiometer with a sensor separation of 1.0 meter. The line spacing was set at $1.0 \mathrm{~m}$ with a sampling interval of $0.125 \mathrm{~m}$. A sample of magnetic data from BP1 is presented in Figure 6.

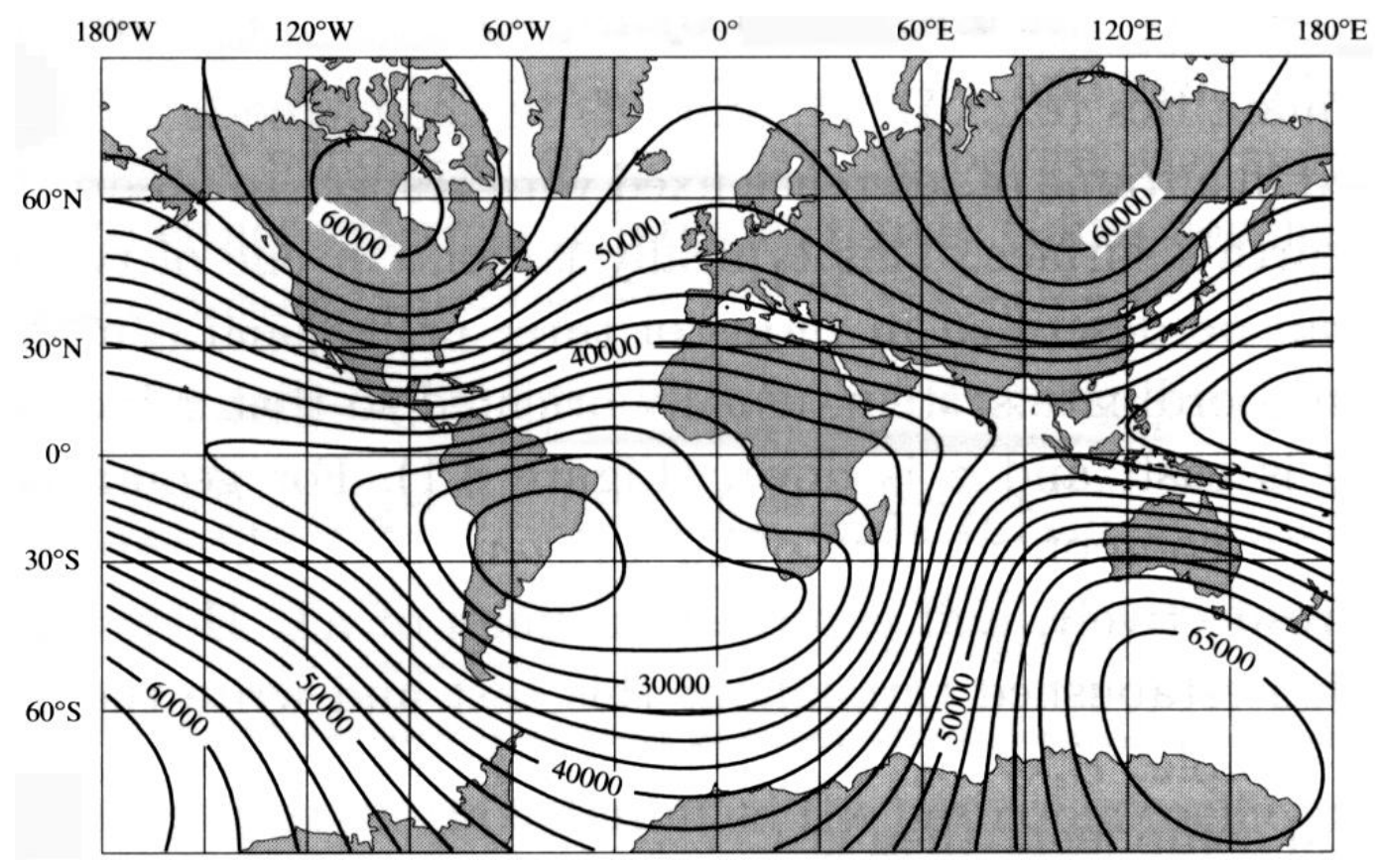

Figure 5: Total Intensity map for the geomagnetic field at a contour interval of 2,500 nT (image taken from http://gravmag.ou.edu/mag_earth/magnetic_field_a.gif). 


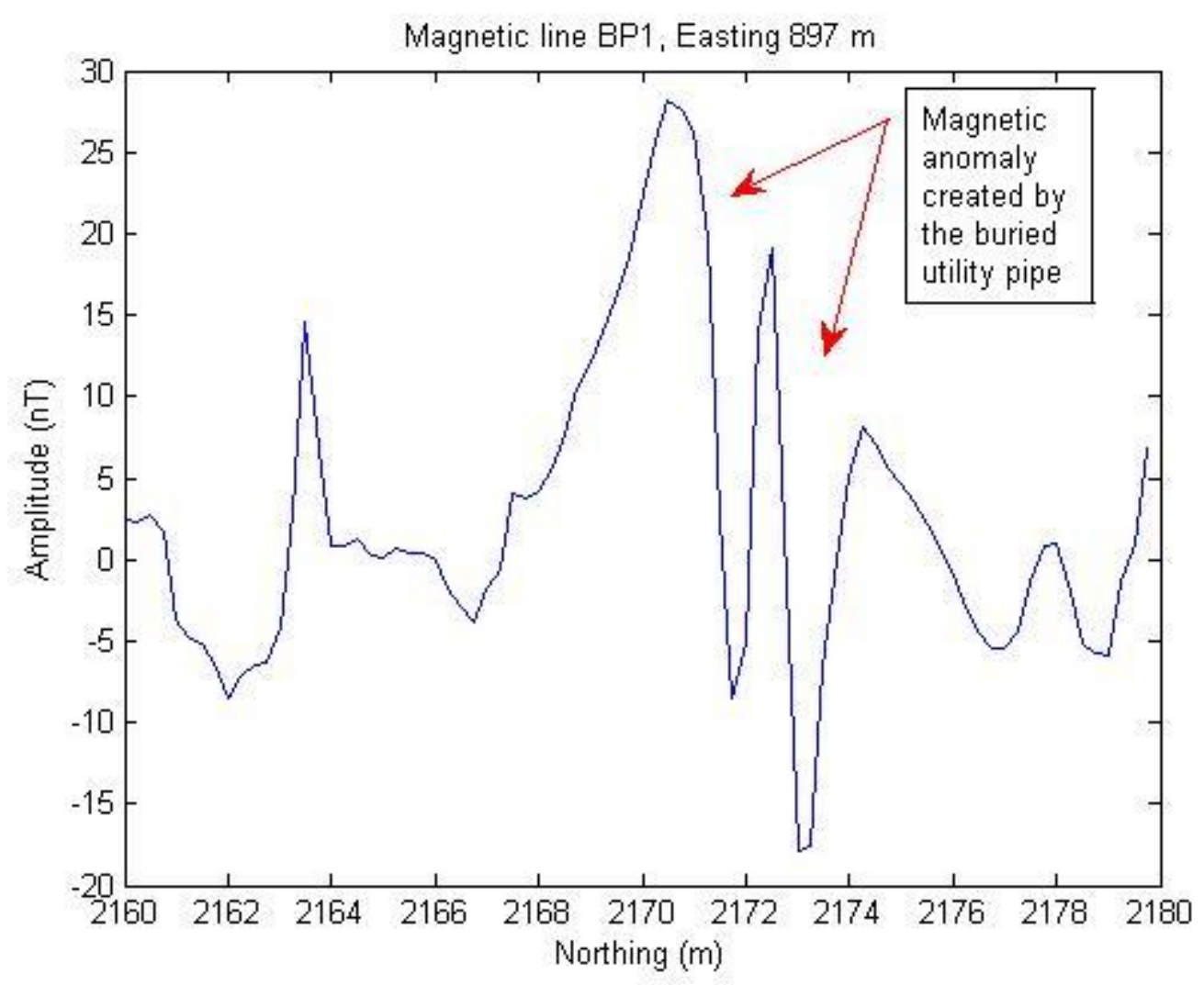

Figure 6: Sample magnetic line from BP1 at 897 meters east, oriented south (left) to north (right). A large magnetic anomaly is created by the buried utility pipe.

\section{Electrical Resistivity}

Electrical resistivity is an active method that applies direct current or low-frequency alternating current at the ground surface through metal probes to measure the potential difference (in Ohm's) between them (Burger, et. al., 2006). Distinct variations in these measurements provide information on subsurface materials as well as the structure of the subsurface. When evaluating the shallow subsurface, electricity is conducted by the amount of water present and the salinity of the water. Two other factors are soil grain size and clay content. Increased clay content, water content, and/or the salinity and decreasing 
grain size, will decrease the resistivity levels (Burger, et. al., 2006). Figure 7 shows typical ranges of resistivity for different geologic materials.

For this research, a dipole-dipole method was used. The equation to calculate electrical resistivity (Ohm's*m) using this array is:

$$
\rho_{\mathrm{a}}=(\mathrm{V} / \mathrm{I})^{*} \mathrm{~K}
$$

where $\rho_{\mathrm{a}}$ is apparent resistivity (Ohm's), $\mathrm{V}$ is the voltage (Volts), I is the current (amp), and $\mathrm{K}$ is a geometric factor of the resistivity array (Ward, 1990). For this research, calculating the resistance without including the geometric factor was sufficient.

Electrical resistivity methods have been used in archeological investigations since the 1950's (Rap and Hill, 2006). They are especially effective at locating depressions or mounds because of the change in the current density. The current density is defined as the current divided by the cross-sectional area of the material through which it is flowing (Burger, et. al, 2006). In a depression, the area is reduced which increases the current density and therefore the resistivity levels are high. In a mound or raised area, the area is greater, decreasing the current density and the resistivity levels fall. Resistivity also is useful for differentiating coarse-grained sands from clay. Finally, this method can be applied at sites where magnetic methods are not effective. This commonly occurs at historic sites where the magnetic signature is so strong that it becomes too noisy to interpret.

Apparent resistivity was applied at Mound City to define the boundaries between strata with significantly different textures. The RM15 Resistance Meter twin probe array was used. A 40-volt output was applied at a $0.5 \mathrm{~m}$ sampling interval with $0.5 \mathrm{~m}$ line spacing. A sample of the resistance data is presented in Figure 9. 




Figure 7: Typical resistivity ranges in rocks and soils (Ward, 1990).

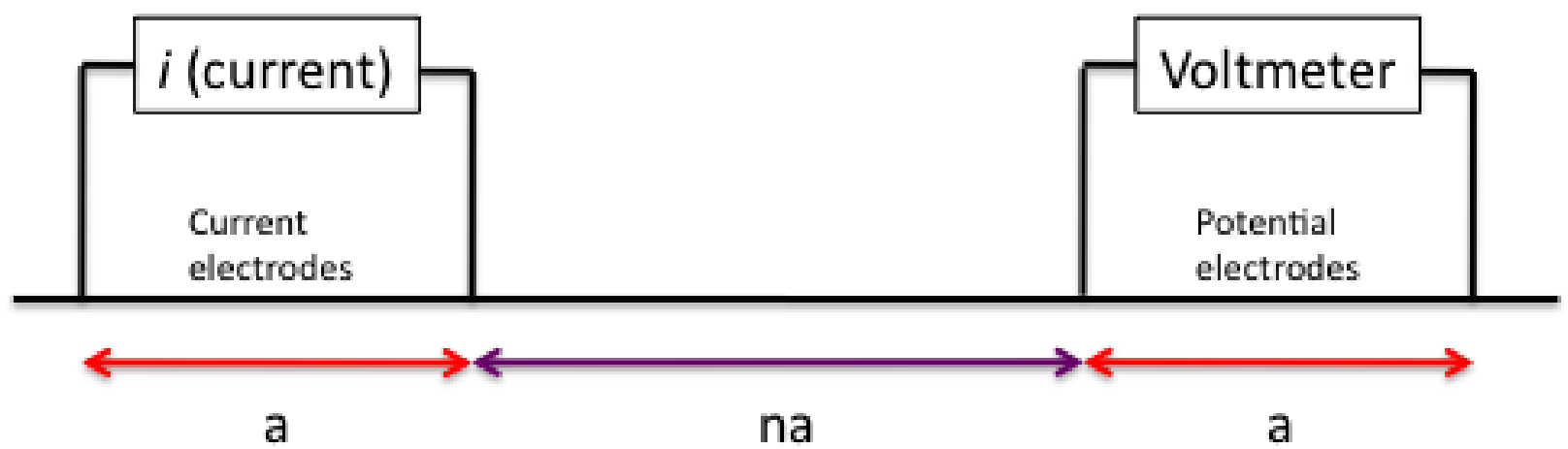

Figure 8: Dipole-Dipole electrical resistivity survey array. "a" is the spacing between the electrodes, and "na" is the spacing between the potential and current electrodes. 


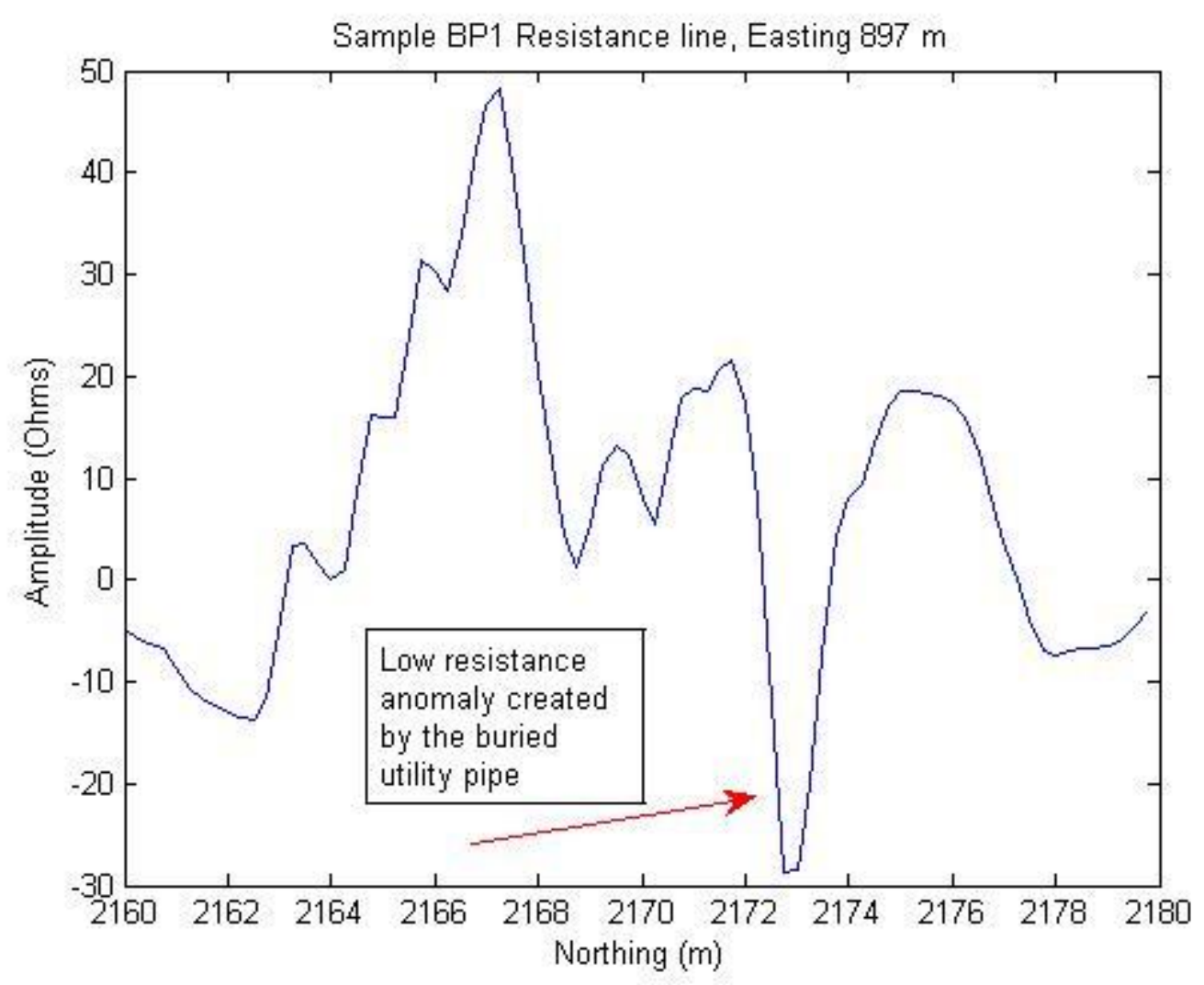

Figure 9: Sample resistance line from BP1 at 897 meters east, oriented south (left) to north (right). A low resistance anomaly is created by the buried utility pipe.

\section{Electromagnetic Induction (Conductivity)}

Conductivity surveys measure, in milliSiemens per meter, the mobility of an electric charge in the presence of an electric field. Electric charges move freely in a conductive material, whereas its reciprocal resistivity impedes this movement (Burger, et al., 2006). It is an active method that carries two coils, one transmitting and one receiving, within two ends of the instrument. An alternating current is sent through the transmitter coil, which generates an electromagnetic field about the coil that is transmitted into the earth. This field interacts with conductors in the soil and generates a secondary electromagnetic field that is then recorded by the receiving coil, which then allows for the measurement of the 
conductivity of the earth at a particular location (Bevan, 1998). When used at appropriate locations, it is much quicker than resistivity surveys because it has no contact with the ground.

The EM38 Conductivity Meter was used for this research, which allows for a maximum depth of roughly $1.5 \mathrm{~m}$ into the ground (Bevan, 1998). Unlike the resistivity meter, this particular conductivity meter is effective over a wide range of soil moisture levels. However, the EM38 Conductivity Meter is much more sensitive to metals and temperature, which must be taken into account and corrected.

Electromagnetic surveys were introduced into archaeology after World War II (Rapp and Hill, 2006). They became more common in North American archeology in the 1970's when a Canadian firm, Geonics Limited, began manufacturing them as portable instruments that could be used for a variety of applications ranging from archeology to environmental monitoring (Johnson, 2006). The EM38 used in this survey has very high sensitivity, which makes it ideal for surveying earthworks (Clay, 2001).

For this research, conductivity surveys were also used to define contrasting strata within the subsurface, as well as identify any buried utility lines or pipes. The sampling interval was set at $0.25 \mathrm{~m}$ with line spacing of $0.5 \mathrm{~m}$. The conductivity data collected for BP2 in the summer of 2010 failed due to instrument error, and so the data were recollected in the summer of 2011 using the same settings and grids. A sample of the conductivity data is presented in Figure 10. 


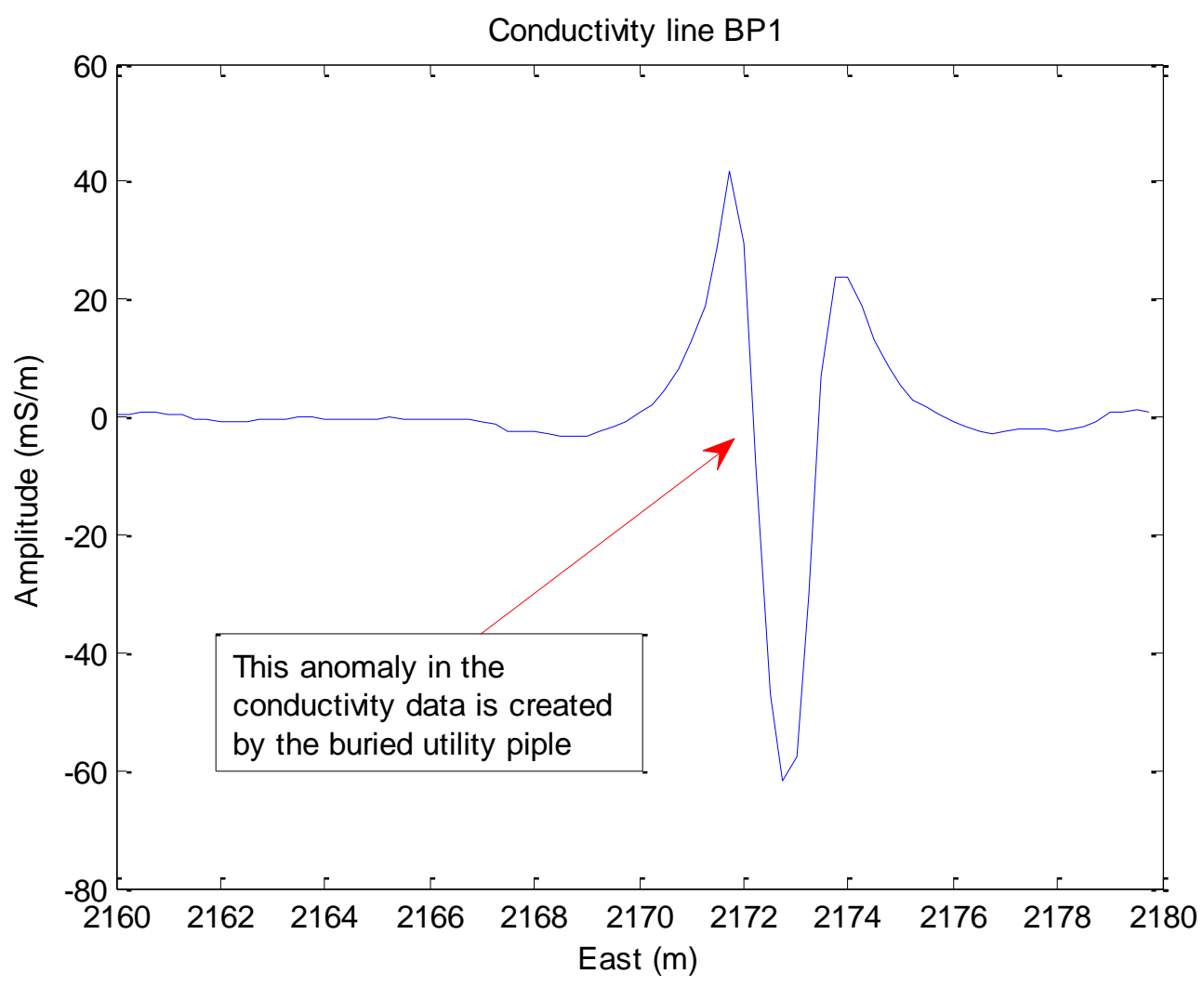

Figure 10: Sample conductivity line from BP1 at 897 meters east, oriented south (left) to north (right). A low conductivity anomaly is created by the buried utility pipe.

\section{B. Geophysical Data Processing}

Each of the datasets collected from the five survey instruments was processed for interpretation with different software and processing steps as described below.

\section{Ground-Penetrating Radar}

Datasets for BP1 and BP2 were processed using MATLAB and then exported into Seismic Microtechnology's Kingdom Suite software for interpretation (Table 3). Similar processing steps were applied to each dataset, with some additional processing operations required for BP2. The first step was to set a time-zero alignment for both datasets. This process corrects for instrument time drift and sets a constant time-zero datum for all traces 


\begin{tabular}{|c|c|}
\hline BP1 & BP2 \\
\hline $\begin{array}{c}\text { 1. Time-zero alignment by 2.935 ns } \\
\text { (MatGPR) }\end{array}$ & $\begin{array}{c}\text { 1. Time-zero alignment by 9.795 ns } \\
\text { (MatGPR) }\end{array}$ \\
\hline $\begin{array}{c}\text { 2. Low-pass frequency filter 750 MHz } \\
\text { (MatGPR) }\end{array}$ & $\begin{array}{c}\text { 2. Low-pass frequency filter 550 MHz } \\
\text { (MatGPR) }\end{array}$ \\
\hline $\begin{array}{c}\text { 3. Background Removal (MatGPR) } \\
\text { 0.09 m/ns (MatGPR) }\end{array}$ & 3. Background Removal (MatGPR) \\
\hline $\begin{array}{c}\text { 4. 2-D Migration using a velocity model of } \\
\text { at Manual gain applied during acquisition } \\
\text { 35, 35, 50 }\end{array}$ & $\begin{array}{c}\text { 4. 2-D Migration using a two-layer } \\
\text { velocity model of 0.1 m/ns and 0.05 m/ns } \\
\text { (MatGPR) }\end{array}$ \\
\hline $\begin{array}{c}\text { 6. Corrected for topography (Matlab) } \\
\text { as BP1). Constant Gain of 100 to all data } \\
\text { points applied during processing (Matlab) }\end{array}$ \\
$\begin{array}{c}\text { 6. Corrected for topography (Matlab) } \\
\text { 7. Exported to SEGY files in Matlab and } \\
\text { uploaded into Kingdom Suite for 3-D } \\
\text { visualization. }\end{array}$ & $\begin{array}{c}\text { 7. Exported to SEGY files in Matlab and } \\
\text { uploaded into Kingdom Suite for 3-D } \\
\text { visualization. }\end{array}$ \\
\hline
\end{tabular}

Table 3: GPR data processing steps for BP1 and BP2.

(Gerlitz et. al, 1993). The next step applied two different filters to both datasets, including a low-pass frequency filter that removed high-frequency noise and a background removal filter that eliminated the horizontal banding created by antenna ringing and revealed the geology of the site. The velocity of propagation in the subsurface was determined for each dataset, which allowed for a 2-D migration of the data to focus and reposition any objects or anomalies to their true position in space (Gerlitz et. al, 1993). A constant gain applied to the BP2 dataset amplified the amplitudes of each trace. Both datasets were corrected for topography using elevation data provided by the National Park Service. There was 
insufficient elevation data to accurately correct the topography for the first $20 \mathrm{~m}$ of BP1, and so only the second half of the grid was corrected for topography (including the embankment wall and the borrow pit). Finally, both datasets were exported to SEG-Y format files and imported into The Kingdom Suite software for 3-D interpretation.

\section{Magnetometry}

A frequency filter at $60 \mathrm{~Hz}$ was applied during acquisition with the single fluxgate gradiometer to avoid sharp spikes from nearby power lines. For processing afterwards, the data were downloaded into Geoplot. A zero-mean traverse filter was applied to remove stripes between the lines of data (Odah et. al, 2009). Next, the dataset was interpolated to achieve the same data sample density in the north-south and east-west directions ( 0.25 by $0.25 \mathrm{~m}$ in each direction) and then a high-pass filter was applied to remove high frequency, small scale spatial details and smooth the datasets. The filter used a Gaussian weighted $10 \mathrm{x}$ 10 window.

The Bartington Grad dataset underwent the same processing steps as the single fluxgate gradiometer, with one exception. It was first downloaded into the Grad601 Datalog Software and exported into Surfer to remove the header information, and then processed in Geoplot. Both datasets were uploaded into MATLAB for interpretation after processing was complete.

\section{Electrical Resistance}

Geoplot was used to process the RM15 resistance data. The first step was to apply a de-spiking filter, which removes erroneous spikes or high amplitude measurements 
detected in the dataset. Next, edge matching aligned all of the data and it was interpolated. Finally, a high-pass filter using a Gaussian weighted 1 x 1 window removed low-frequency noise and the geological background response which is common in resistivity data. After the processing steps were complete, the data was uploaded into MATLAB for interpretation.

\section{Electromagnetic Induction (Conductivity)}

The EM38 Conductivity datasets were downloaded into the Windows Dat38W software and then exported into Surfer to remove the header information so that it could be processed in Geoplot. This dataset processing included a zero-mean traverse, interpolation, low-pass filter using a Gaussian weighted $1 \times 1$ window, and a median filter before being uploaded into MATLAB for interpretation.

\section{Trenching and Auguring}

After both borrow pits were surveyed with the geophysical equipment, a trench was dug into each of them to evaluate the soil stratigraphy. The trench for BP1 was an extension of a trench dug through the embankment wall by Mark Lynott of the Midwest Archeological Center during the summer of 2009. In the summer of 2010, Mark Lynott and I dug a 1x2 m trench into BP2 that went 50-60 cm below the surface. A cross-section for each trench was constructed using a string and level. Finally, Rolfe Mandel of the Kansas Geological Survey described and sampled the walls of the trench.

After the geophysical datasets were processed and interpreted, locations were selected in both borrow pits for ground-truthing with a 3-inch bucket auger. Auguring was 
conducted in both borrow pits in July of 2011. Figures 11 and 12 show the survey grids for both borrow pits, as well as the location of the trenches and auger holes.

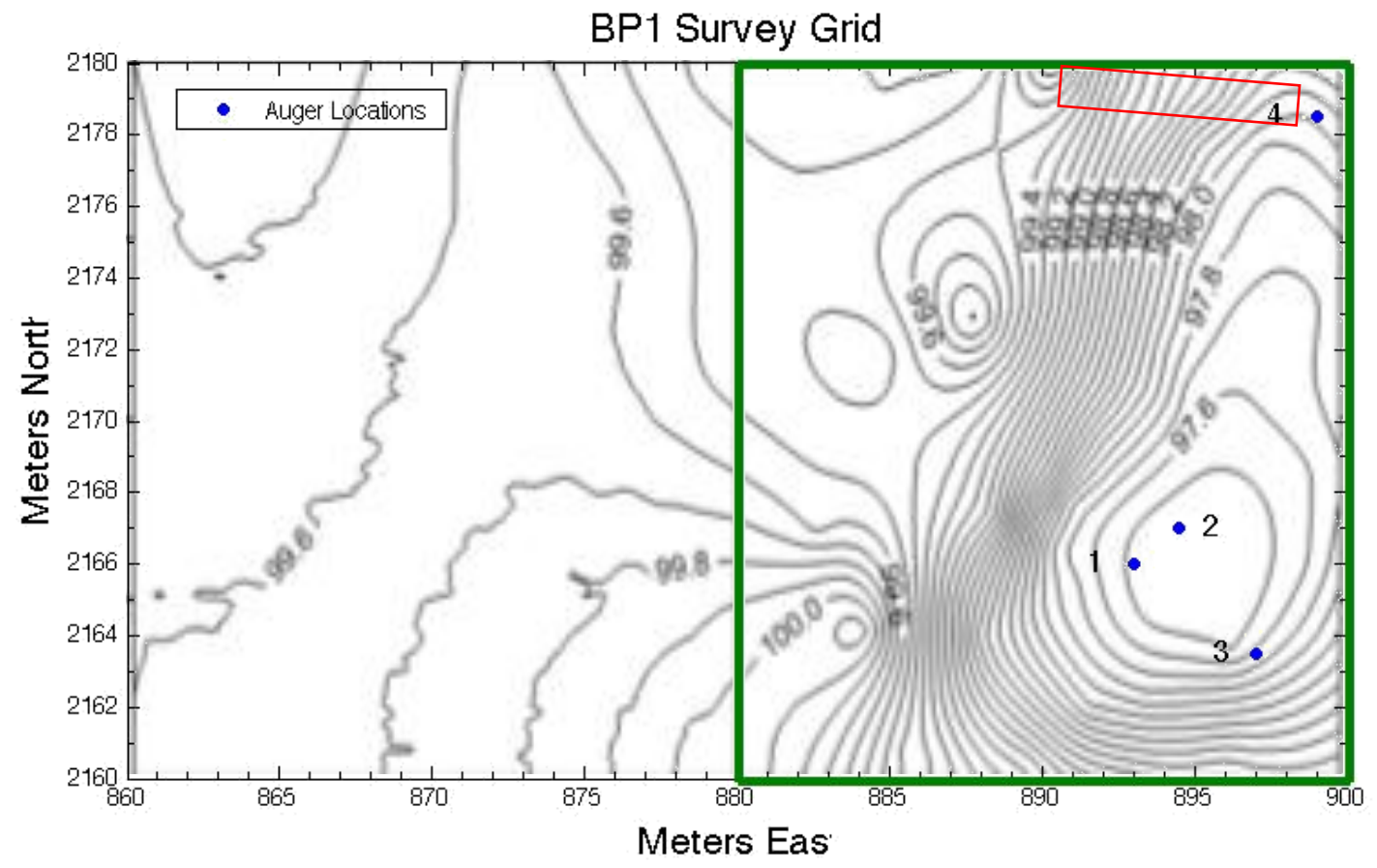

Figure 11: Contour map (m) of the survey grid for BP1. The GPR and dual magnetometer surveys were run over the entire $40 \times 20$ meter grid. The green box shows the grid for the single magnetometer, electrical resistivity, and conductivity surveys. The red rectangle represents the location of the trench and the numbered blue dots identify auger locations. 


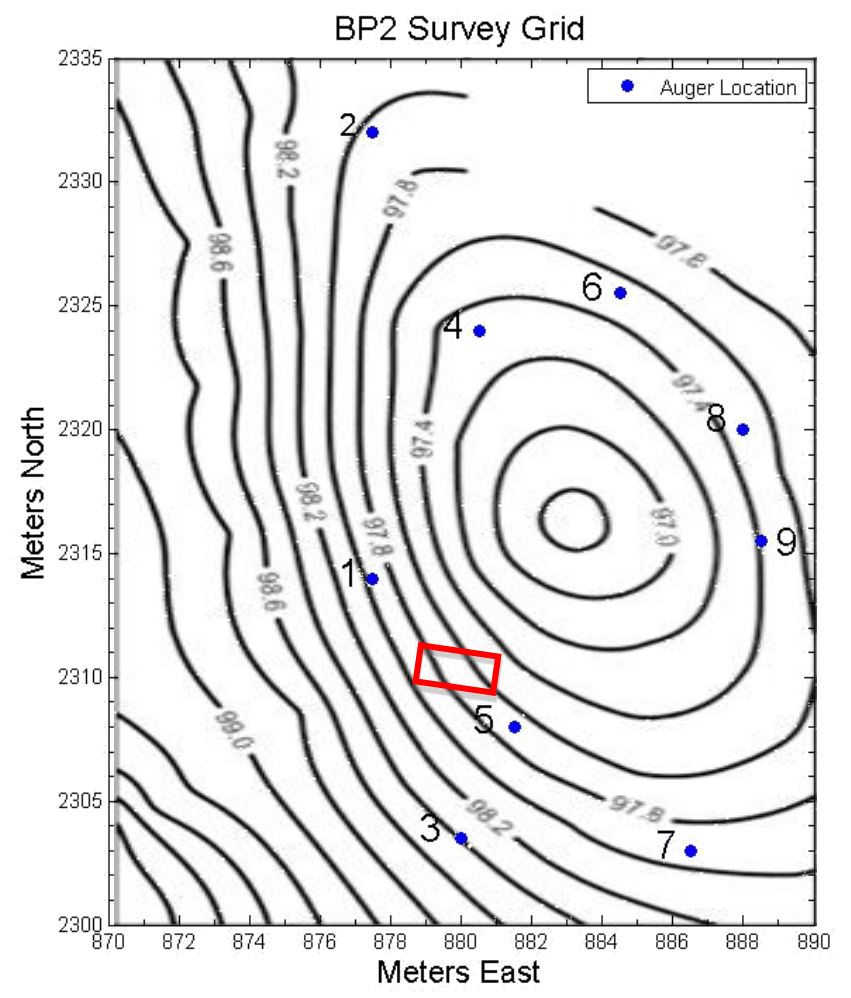

Figure 12: Contour map (m) of the survey grid for BP2. The red rectangle represents the trench dug in July of 2010, and the auger locations are identified by the blue numbered dots. 


\section{Results}

\section{A. BP1 Geophysical Results}

The geophysical data from BP1 revealed several historic cultural features present within the borrow pit. No prehistoric features, including the clay lining, were found in these datasets. A detailed description of the individual results for each method is described.

\section{Magnetometry}

The magnetic data from both the single fluxgate gradiometer and the dual fluxgate gradiometer are presented in Figure 13. The two datasets show the same results, with the exception that the dual gradiometer covered a grid area that was $40 \mathrm{~m}$ across, whereas the single gradiometers grid was $20 \mathrm{~m}$ across. The remnants of the buried railroad tracks can be seen in the dual gradiometer data along the east side of the grid. The embankment wall shows up as a positive linear anomaly in both datasets running NNE-SSW. A large linear dipole representing the buried utility pipe trends NE-SW through the center of the borrow pit in both images. The color magnitudes of both datasets were set to +/- $10 \mathrm{nT}$ in order to reveal any potential prehistoric features with weak signals.

\section{Electrical Resistance}

The resistance data also have a larger grid of $40 \mathrm{~m}$ across (Figure 14). The buried railroad tracks can be seen in the western half of the grid, and the embankment wall shows up as a higher resistance feature to the east of the center of the grid running NNE-SSW. The buried utility pipe appears as a linear, low-resistance feature, with contrasting areas of high resistance surrounding it indicating that no clay lining remains in the center of the 
borrow pit. The color magnitude of the dataset was set to $+/-10$ ohms to enhance any prehistoric features with a weak signal that may occur below the surface.

Electromagnetic Induction (conductivity)

The conductivity data were collected over a $20 \mathrm{~m}$ grid (Figure 14). The embankment wall appears as a linear feature running NNE-SSW with low electrical conductivity values. The buried utility pipe has alternating high and low values and it runs below the embankment wall, a pattern that was not observed in the other geophysical datasets. The color magnitude of the dataset was set to $+/-10 \mathrm{mS} / \mathrm{m}$ per meter to enhance weak signals.

\section{Ground-Penetrating Radar}

The results of the GPR survey are shown in figures 15 and 16. For BP1, a velocity of $0.09 \mathrm{~m} / \mathrm{ns}$ was calculated, with a total of 481 samples per trace. There was not enough data to accurately correct for topography for the first $20 \mathrm{~m}$ across the scan axis, and so the data were separated into two grids: BP1-1 for the first $20 \mathrm{~m}$, and BP1-2 from 21-41 m across the scan axis. A time slice at 10 nanoseconds from BP1-1 shows a clear image of the buried railroad tracks dating to the Camp Sherman occupation (Figure 15a). In Figure 16, a strong anomaly representing a buried utility pipe that was left behind from the Camp Sherman occupation can be seen from 15-21 m across the grid at a time interval of 75-80 ns, which is equivalent to a depth of roughly $70 \mathrm{~cm}$. 
a)

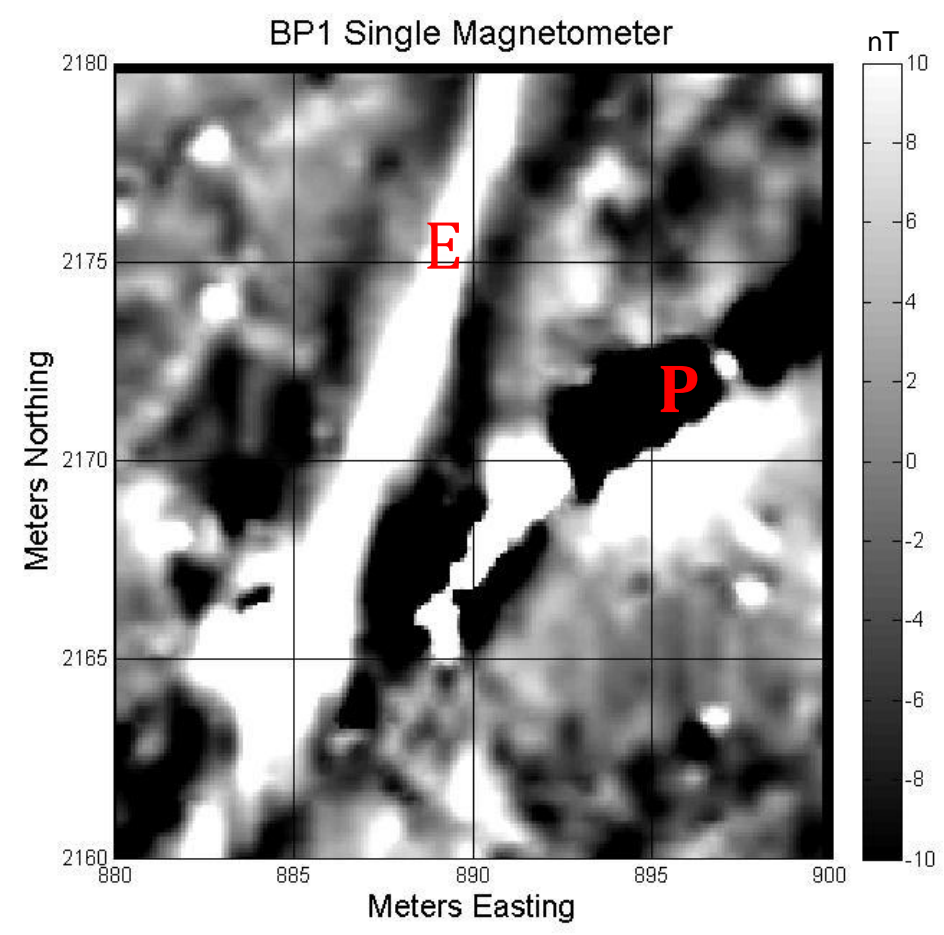

b)

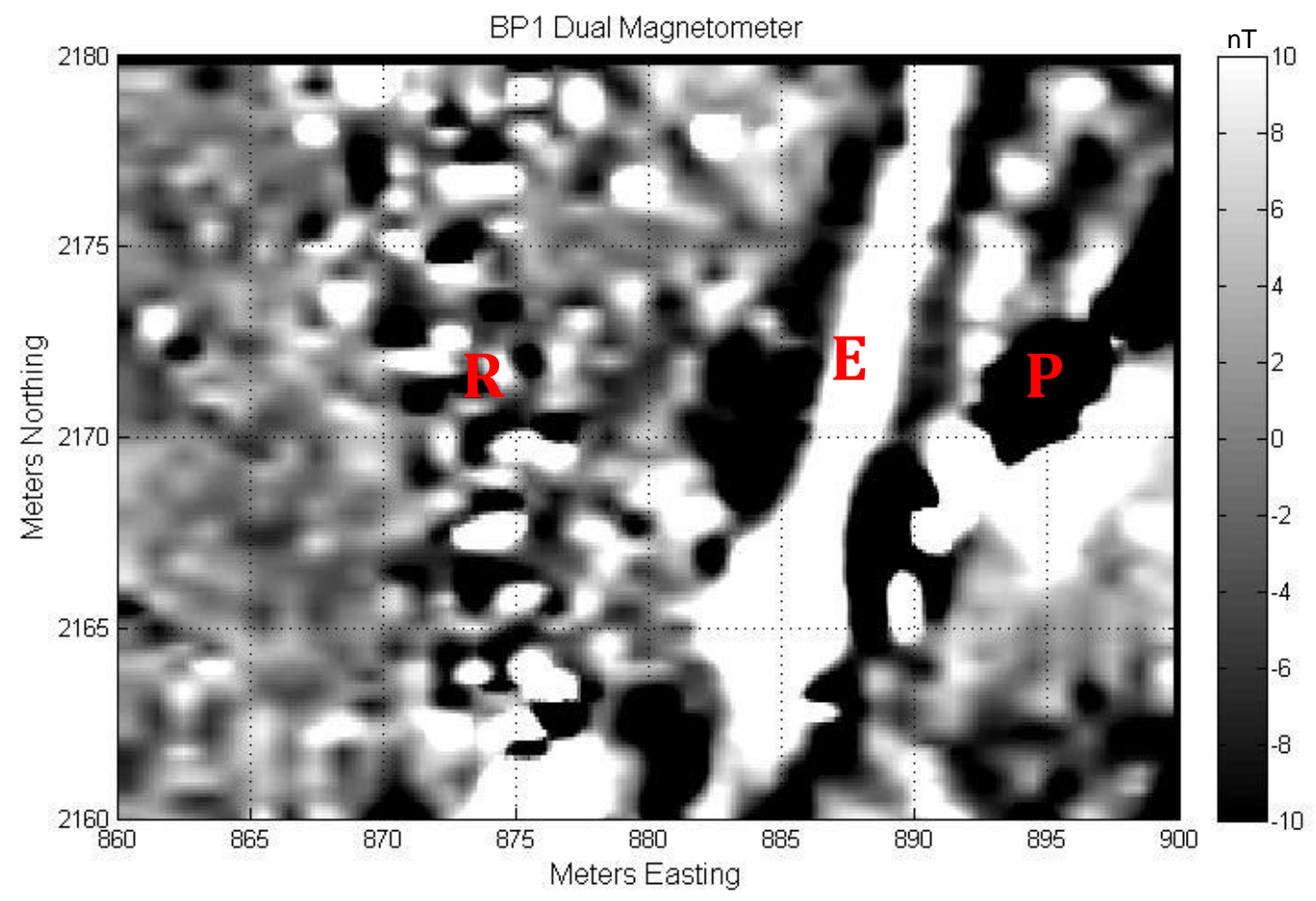

Figure 13: BP1 magnetic data. The single fluxgate gradiometer dataset is presented in a, and the dual fluxgate gradiometer dataset is presented in b. E represents the embankment wall, $\mathrm{P}$ is the buried utility pipe, and $\mathrm{R}$ represents the buried railroad tracks. 




b)

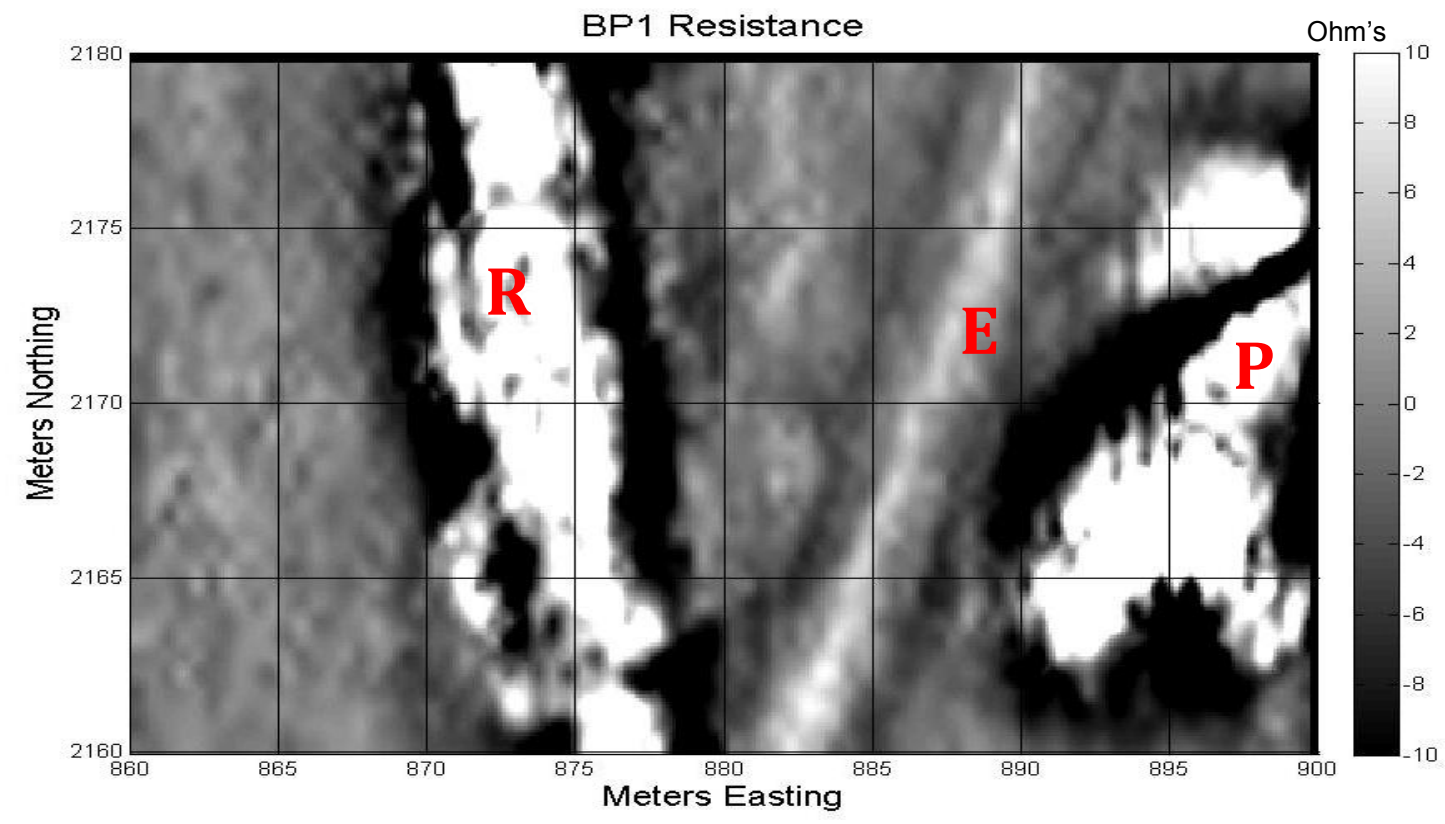

Figure 14: BP1 conductivity data (a) and resistance data (b). E represents the embankment wall, $\mathrm{P}$ is the buried utility pipe, and $\mathrm{R}$ represents the buried railroad tracks. 


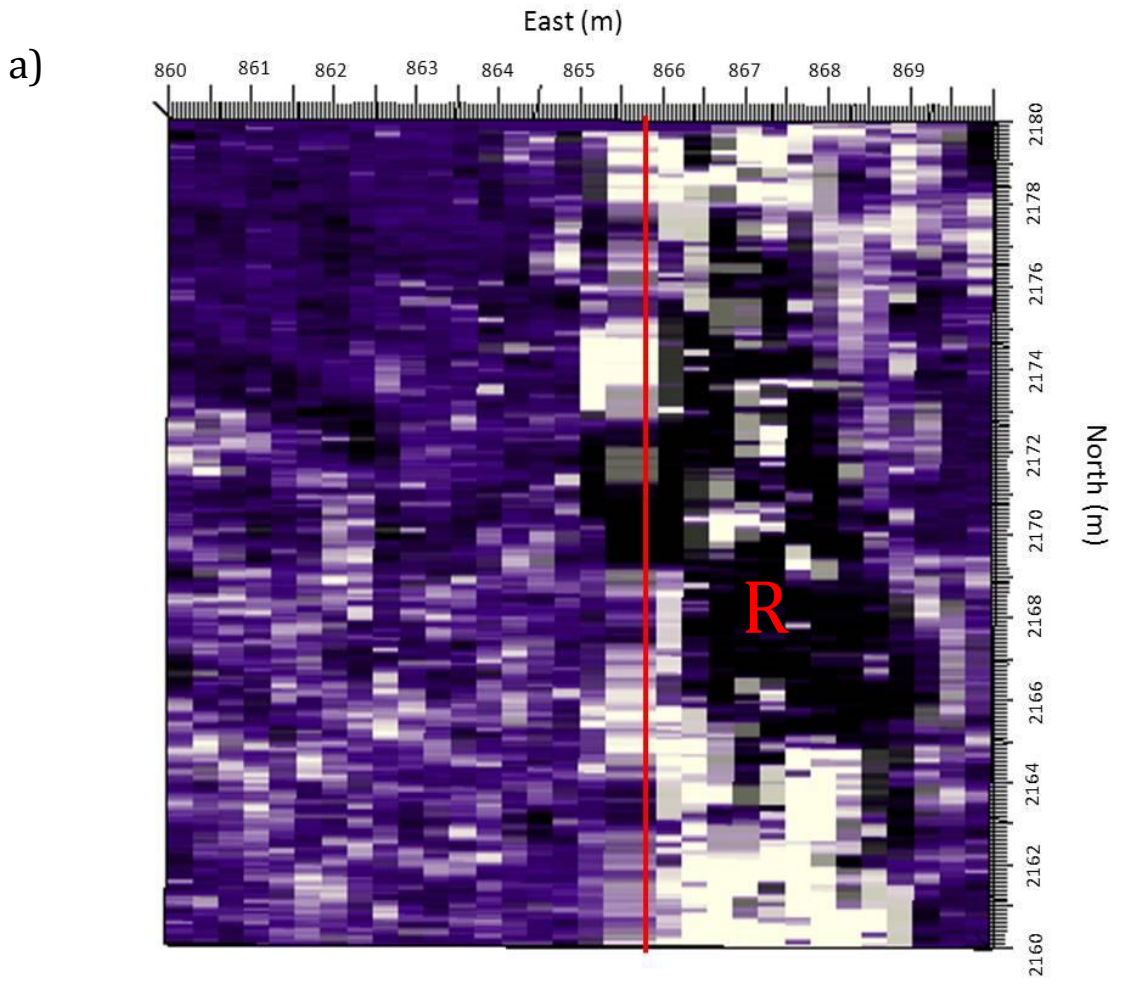

b)

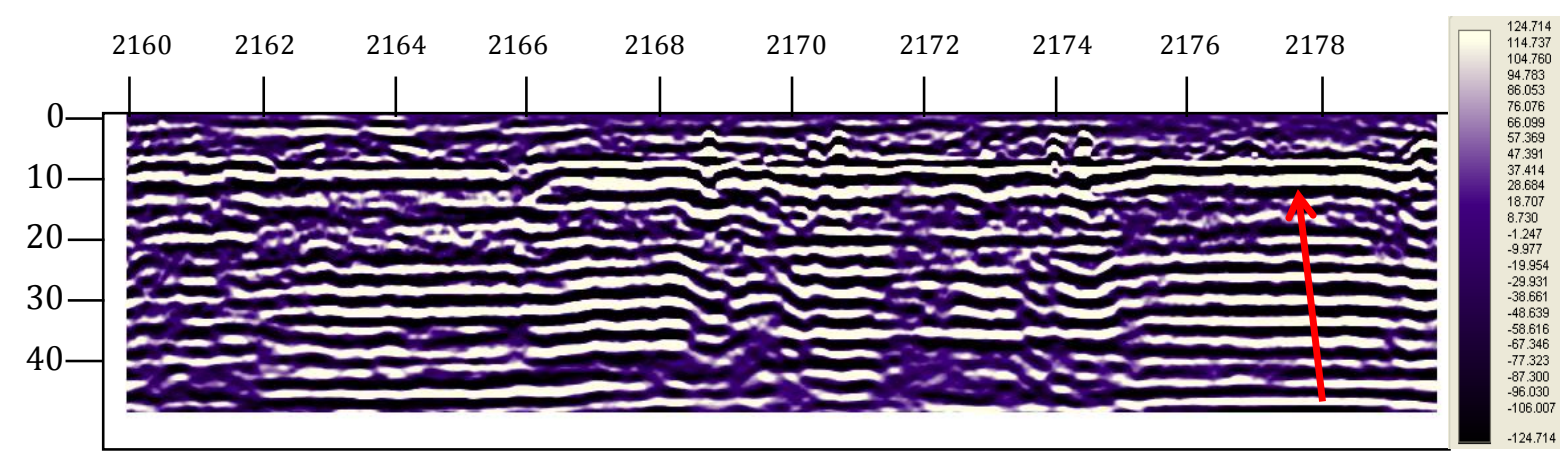

Figure 15: GPR Time Slice and Cross Section from BP1. a) Time slice at a $10 \mathrm{~ns}$ below the surface from BP1-1. The R represents the remnants of the railroad track that is also seen in the magnetic and resistance data. b) Cross section at $12.5 \mathrm{~m}$ Easting through the time slice (location shown by the red line). The strong amplitude layer at $10 \mathrm{~ns}$ (indicated by red arrow) is the buried railroad track. 
North (m)

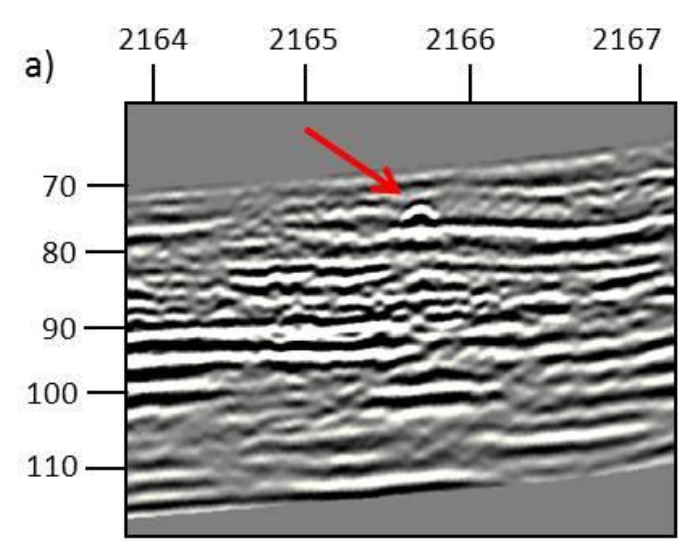

c)

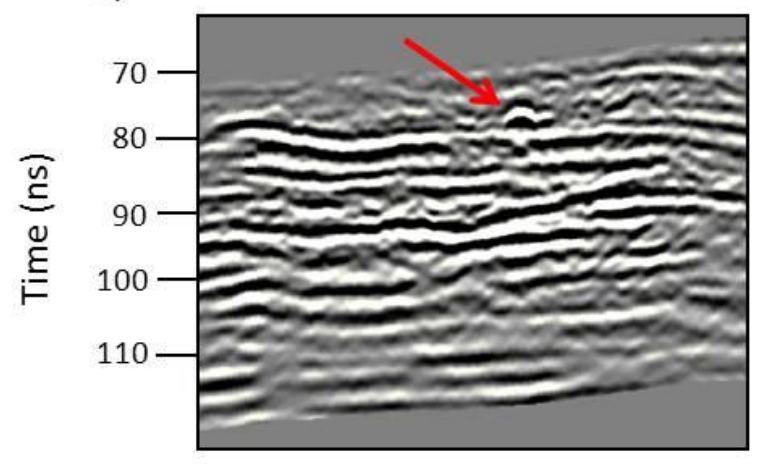

e)

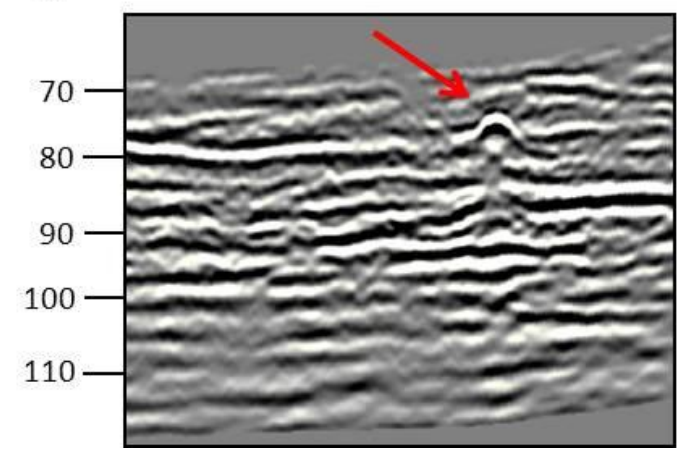

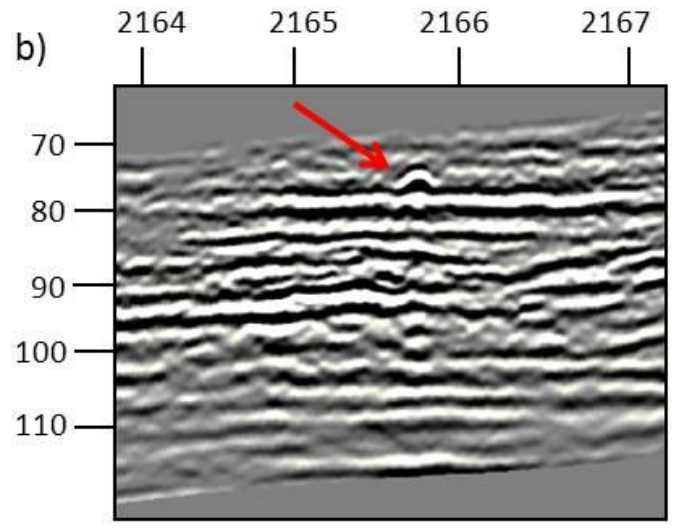

d)

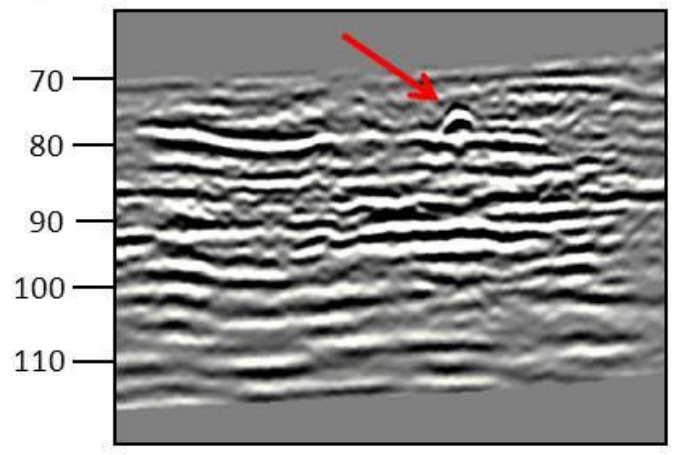

f)

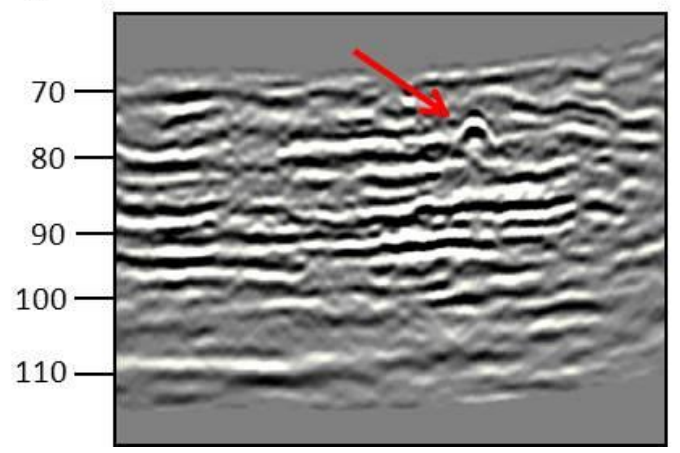

Figure 16: GPR cross section panel at a) 897 m east, b) 897.5 m east, c) 898 m east, d) 898.5 m east, e) $899 \mathrm{~m}$ east, and f) $899.5 \mathrm{~m}$ east. The red arrow is pointing to the buried utility pipe that can be seen moving through the lines at 2165 to $2166 \mathrm{~m}$ north at a time interval of 75-80 ns. This is equivalent to a depth of roughly $70 \mathrm{~cm}$. Black colors correspond to negative amplitudes; white colors correspond to positive amplitudes. 


\section{B. BP2 Geophysical Results}

The geophysical results from BP2 revealed several historic and prehistoric archeological features present within the borrow pit, including remnants of the clay lining. Unlike BP1, there were no historic cultural features emplaced into this borrow pit. A detailed description of the individual results for each method is described.

\section{Magnetometry}

The magnetic data from both the single fluxgate gradiometer and the dual fluxgate gradiometer are presented in Figure 17. The two datasets show very similar results, with only a slight change in resolution. A modern compacted trail can be seen running NW-SE in the western half of the grid, and several prehistoric and historic anomalies are scattered throughout the area. A unique circular feature is visible in both of the datasets and correlates well with the GPR data, but the source of it is unknown. The color magnitudes of both datasets were set from $+/-5 \mathrm{nT}$ in order to enhance any prehistoric features with weak signals.

\section{Electrical Resistance}

The resistance dataset (Figure 18a) also clearly depicts the modern compacted trail that is running NW-SE in the western half of the grid. The most interesting aspect of the electrical resistivity data is the alternating spots of high and low resistivity values. Clay should have low resistance values and gravel should have higher resistance values, and so these locations are most likely associated with the remaining areas of emplaced clay versus the areas that have gravel directly beneath the topsoil. This dataset correlates very well with the results of the trench that was dug into the borrow pit, shown in Figure 9. It also 
correlates well with the GPR data. The color magnitude of the dataset was set to +/- 10 ohms in order to enhance prehistoric features that may be present.

\section{Electromagnetic Induction (conductivity)}

The conductivity data for BP2 were re-collected in July of 2011 before the auguring was conducted. The modern trail that is depicted running NW-SE in the western half of the grid was detected in this dataset. A correlation can be seen between this dataset and the resistance dataset for identifying areas where the clay lining is no longer present, as indicated by areas of higher lower conductivity and higher resistance (Figure 18b). The color magnitude of the dataset was clipped from 3-10 mS/m in order to enhance any features with weak signal present.

\section{Ground-Penetrating Radar}

Results of the GPR for BP2 are presented in Figures 19, 20 and 21. The noise level below 50 nanoseconds and below in this dataset is very high, which makes it difficult to interpret. However, the area of interest is the first meter below the surface and so the upper 10 nanoseconds along the GPR profiles are sufficient for this study.

This dataset correlated well with the resistance and auger data for tracking the remnants of the clay lining. The tops of the different soil horizons can be tracked through each radar line when auger data is present (figures 19 and 20). The geophysical interpretation between soil horizons in these figures is based off of the resistance data, which can also be seen in figures 19 and 20. Unit II represents the clay lining, and can be seen pinching in and out throughout the dataset, with varying thicknesses. The transition 
into Unit III, the sand and gravel, correlates well with a significant decrease in amplitude seen in all of the lines. The radar data shows a great correlation with the corresponding resistance data, higher resistance indicate areas where the clay lining is not present, and lower resistance indicate areas where the clay lining is present. In the areas where no clay lining exists, the top of Unit III in the GPR data is generally shallower.

The circular shape that was detected in both magnetometer datasets is also seen in the GPR data at a depth of 50-55 cm below the surface, which is equivalent to the depth of the magnetic data. The shape is not quite as defined as seen in the magnetic data, but they follow the same general pattern (Figure 21). The panels in the figure show a progression from the bottom of the feature to the top of the feature. 
a)
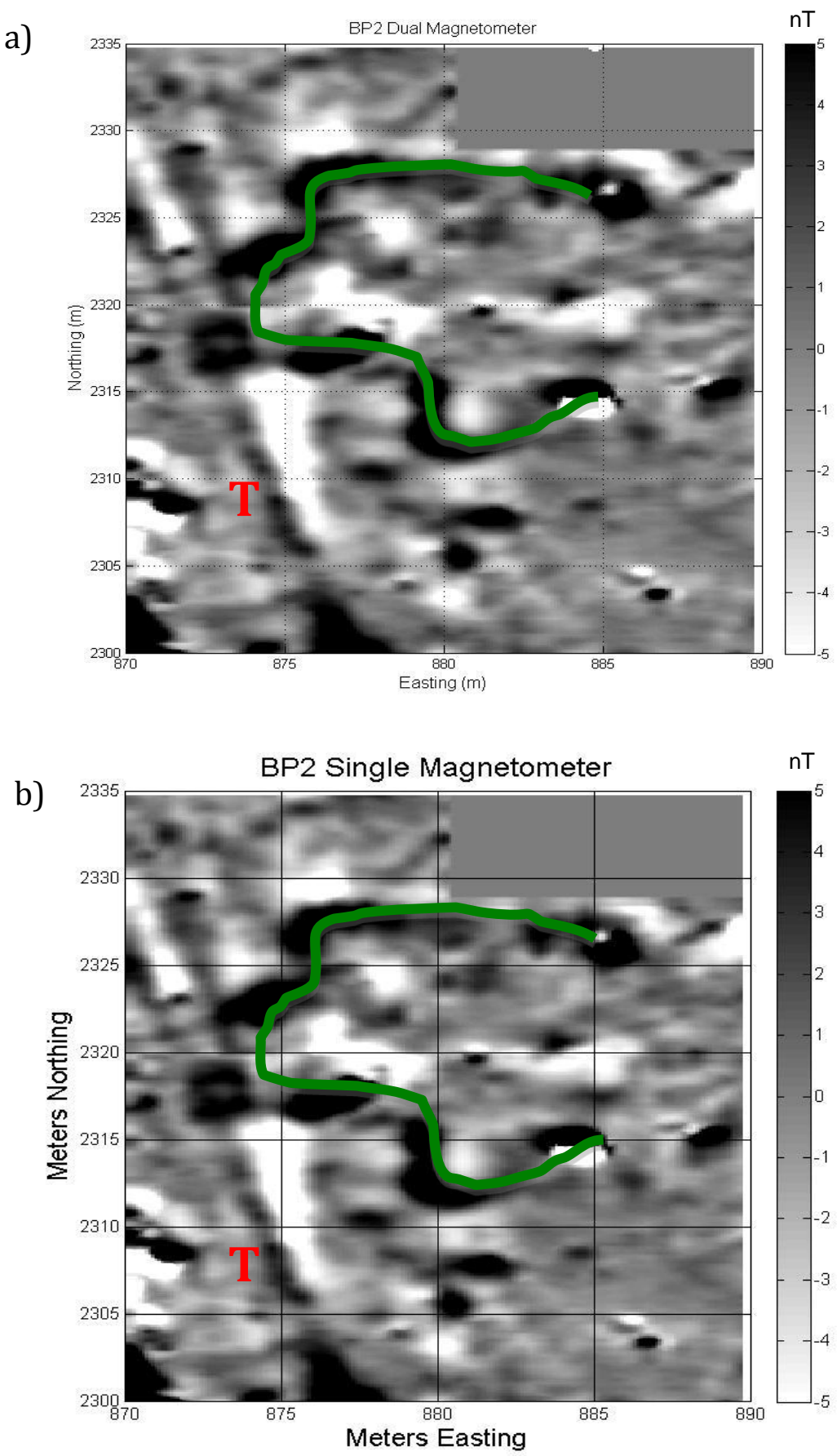

Figure 17: BP2 magnetic data. The dual fluxgate gradiometer dataset is presented in a, and the single fluxgate gradiometer dataset is presented in $\mathrm{b}$. T represents the modern trail. There appears to be a circular shape present (outlined in green) in both datasets, but its source is unknown. 
a)



b)

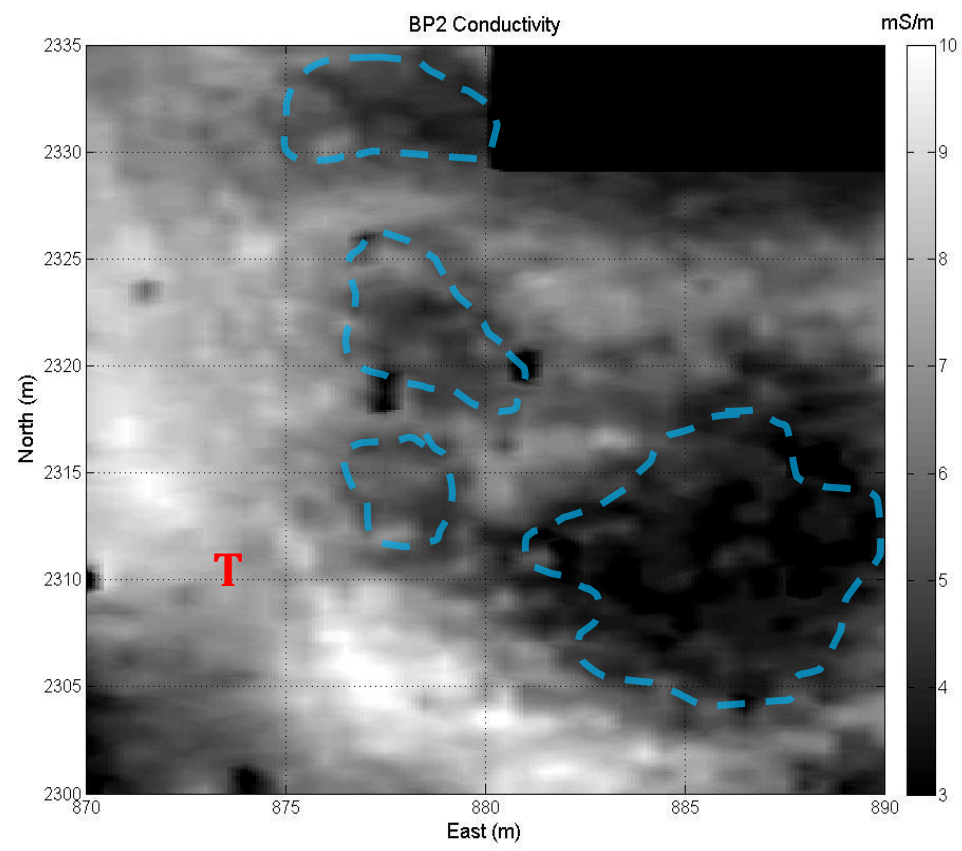

Figure 18: BP2 resistance data (a) and conductivity data (b). T represents the modern trail that exists there today. A correlation can be seen between the two datasets, particularly at identifying areas where the clay lining is no longer present (outlined in blue). 

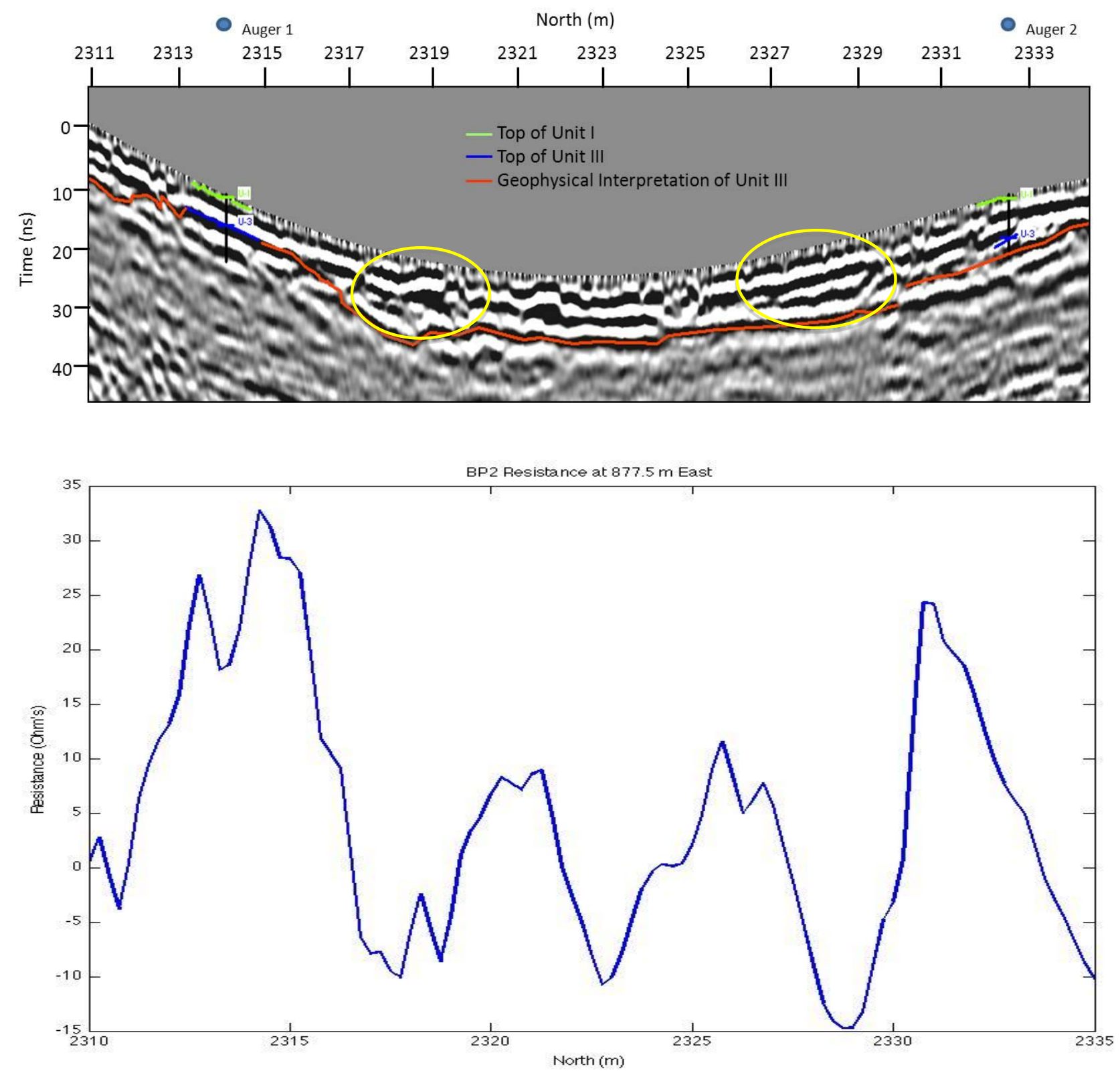

Figure 19: BP2 GPR Survey Line at 877.5 m east moving north and corresponding resistance line. Black colors correlate with positive amplitudes, and white colors correlate with negative amplitudes. The green and dark blue lines are the tops of Units I and III from the augers, respectively. See Table 4 for unit descriptions. The orange line is the interpreted boundary of Unit III. Clay lining is present in the yellow circled areas and pinches out on either side. 



Figure 20: BP2 GPR Survey Line at 881.5 m east moving north and corresponding resistance line. Black colors correlate with positive amplitudes, and white colors correlate with negative amplitudes. The green line represents the top of Unit I, the red line represents the top of Unit II, and the dark blue line represents the top of Unit III in the auger hole. The light blue and orange lines are the interpreted boundaries of Units II and III, respectively. The areas where clay is present are much thicker than the areas without, and the clay layers pinch out as indicated by the yellow arrows. 

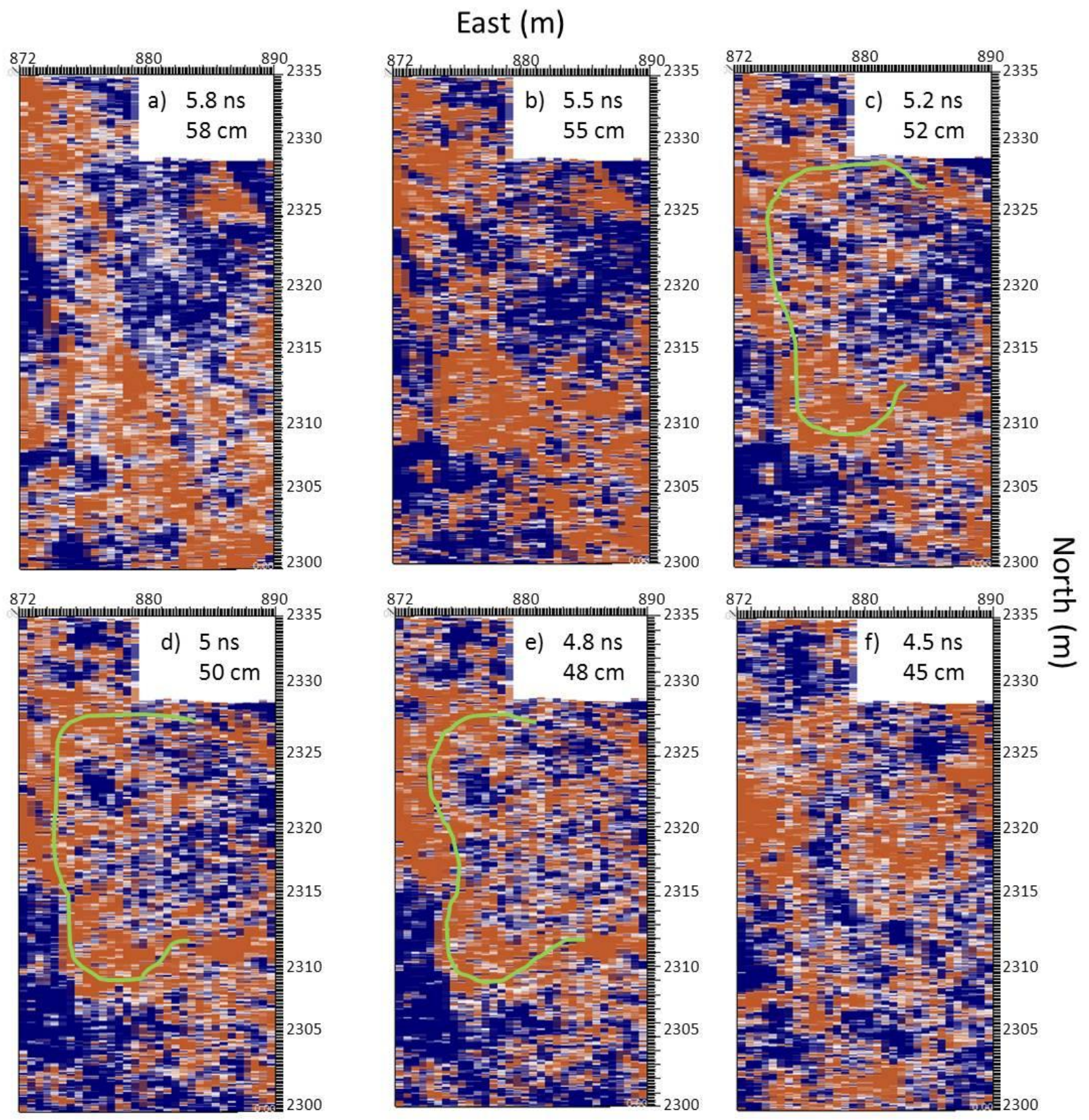

Figure 21: GPR Time Slice Panel from BP2. Six time slices from BP2 that show the correlation between the unique shape seen in the magnetic data with the GPR data. The trail predominates below in a, but the shape becomes more defined in b and c, and is a good match in $\mathrm{d}$. It begins to lose the shape as you move further up as seen in e and $\mathrm{f}$ and the trail signature becomes more predominant again. 


\section{$\underline{\text { C. Trench and Auger Results }}$}

The first trench excavated into BP1 in the summer of 2009 showed evidence of an emplaced clay layer (Unit II), beginning at the base of the embankment wall and extending down into the borrow pit (Figure 22). Table 4 provides a complete description of the units. There are four stratigraphic units located within the embankment wall in BP1, but as you move further down the trench into the borrow pit, three different units appear.

The trench excavated into BP2 in the summer of 2010 also exhibited the clay liner (Unit II), but in only half of the test unit (Figure 23). The clay liner pinches out along the eastern half of the trench. There were a total of three different units in this trench; Units II and III correspond with Units II and Ia from the trench in BP1, respectively. A small gullylike feature was recorded in the west wall of the trench in BP2, which matches up well with a dip in the GPR data (Figure 23).

Integrated geophysical maps of each borrow pit were created in order to select auger locations. For BP1, the resistance, magnetic, and conductivity datasets were combined as seen in Figure 24. The base map in grayscale is the resistance dataset, the green contour map is the magnetic dataset, and the pink contour map is the conductivity dataset. All three datasets emphasize the location of the buried utility pipe and the embankment wall. Areas of interest were compared with the GPR dataset as well. In BP1, areas of interest were defined by the presence of anomalies in two or more geophysical datasets. Auger locations were chosen in areas where one or more geophysical methods showed evidence of an anomaly or area of interest.

For BP2, the resistance and magnetic datasets were combined (Figure 25). The base map in grayscale is the resistance dataset, the green contour map is the magnetic data, and 
the red line outlines the circular shape seen in the magnetic and GPR datasets. The conductivity dataset was not used for this map. The resistance dataset highlights the location of remnants of the clay lining, while the magnetic dataset shows several locations where cultural features may be present. One interesting view is that the circular shape in the magnetic data seems to follow the shape of the clay lining indicated by the resistance data. In BP2, areas of interest were defined by evidence from both the integrated map and the GPR data that the emplaced clay lining still remained. Auger locations were chosen in areas to confirm or refute the presence of clay lining based on the resistance and GPR data, as well as areas where cultural features may be present as indicated by the magnetic dataset.

In BP1, auger holes 1, 2, and 3 did not contain any cultural or archeological features. Auger hole 4 in BP1 revealed a very thin remnant of the clay lining. In BP2, auger holes 3, 4, 5, 7 and 9 all contained the clay lining as indicated by the geophysical data. Auger holes 6 and 8 in BP2 revealed historic archeological artifacts, and auger hole 4 in BP2 revealed one prehistoric flake. Augers 1 and 2 in BP2 did not contain any cultural or archeological features. Detailed descriptions of the results of auguring are presented in Appendix A. A final map of BP2 showing the areas where clay is still present according to the resistance, GPR, and auger results and their associated thicknesses is presented in Figure 26. The numbers in black are known thicknesses from the auger data. The numbers in blue are the estimated depths according to the GPR data. 


\begin{tabular}{|c|c|}
\hline $\begin{array}{l}\text { BP1 Unit } \\
\text { Number } \\
\end{array}$ & Soil Description \\
\hline Ia & $\begin{array}{l}\text { Light brownish gray (10YR 6/2) sand and gravel, brownish gray (10YR 5/2) moist; } \\
\text { single grain; soft, loose. }\end{array}$ \\
\hline Ib & $\begin{array}{l}\text { Yellowish red (5YR 4/6) gravelly loam, reddish brown (5YR 4/4) moist; weak medium } \\
\text { subangular blocky structure parting to weak fine subangular blocky; hard, firm; few } \\
\text { distinct, discontinuous reddish brown (5YR 4/3, dry) clay films on ped faces and clay } \\
\text { bridges between sand grains; common well rounded to sub-rounded pebbles and few } \\
\text { cobbles scattered through the matrix. }\end{array}$ \\
\hline II & $\begin{array}{l}\text { Yellowish red (5YR 4/6) gravelly clay loam, reddish brown (5YR 4/4) moist; moderate } \\
\text { medium prismatic structure parting to moderate fine subangular blocky; hard, firm; } \\
\text { common distinct discontinuous reddish brown (5YR 4/3) clay films on ped faces and } \\
\text { clasts; many well-rounded to sub-rounded pebbles and cobbles; common very fine } \\
\text { roots; abrupt wavy boundary. }\end{array}$ \\
\hline III & $\begin{array}{l}\text { Yellowish red (5YR 5/6) loam, yellowish red (5YR 4/6) moist; common masses of } \\
\text { strong brown (7.5YR 5/6) loam, brown (7.5YR 4/4) moist; moderate medium } \\
\text { prismatic structure parting to moderate fine subangular blocky; hard, firm; common } \\
\text { inclusions of sand and gravel; common distinct, discontinuous reddish brown (5YR } \\
\text { 4/3, dry) clay films on ped faces; common to many well rounded to sub-rounded } \\
\text { pebbles and few fine cobbles scattered through the matrix; few lenses of gravel; } \\
\text { common fragments of charcoal; few fine and very fine roots; abrupt wavy boundary. }\end{array}$ \\
\hline IV & $\begin{array}{l}\text { Brown (7.5YR 4/4) and reddish brown (5YR 4/4) gravelly loam, dark brown (7.5YR } \\
\text { 3/4) and dark reddish brown (5YR 3/4) moist; massive to single grain; soft, loose; } \\
\text { many pebbles and cobbles; common fragments of coal; common krotovina; few fine } \\
\text { and very fine roots; abrupt wavy boundary. }\end{array}$ \\
\hline $\mathbf{V}$ & $\begin{array}{l}\text { Brown (7.5YR 4/4) gravelly loam, dark brown (7.5YR 3/4) moist; massive to single } \\
\text { grain; soft, loose; many pebbles and cobbles; common fragments of coal; common } \\
\text { krotovina; many fine and very fine roots; abrupt wavy boundary. }\end{array}$ \\
\hline $\begin{array}{l}\text { BP2 Unit } \\
\text { Number }\end{array}$ & Soil Description \\
\hline $\mathbf{I}$ & $\begin{array}{l}\text { 10YR } 4 / 3 \text { (dry) silt loam, weak, fine granular structure. Friable, many biogenic features, } \\
\text { open insect burrows, and worm casts. Many fine and very fine roots. } 30-40 \text { percent } \\
\text { gravel. }\end{array}$ \\
\hline II & $\begin{array}{l}\text { 5YR3/4 (moist) 5YR4/4 (dry) clay loam. Moderate, medium prismatic parting to } \\
\text { moderate fine subangular blocky. Hard and firm. Common distinct continuous } 5 \text { YR } 4 / 3 \\
\text { clay films on ped faces, } 5 \text { YR3/ } 2 \text { clay flows in macro pores. Common fine and very fine } \\
\text { with some medium roots, and common worm casts. }\end{array}$ \\
\hline III & $\begin{array}{l}\text { 10YR5/4 sand and fine gravel. Loose, single-grained. Upper boundary is abrupt and } \\
\text { wavy. }\end{array}$ \\
\hline
\end{tabular}

Table 4: Soil Descriptions of trench units. A total of nine units were identified in the trenches from BP1 and BP2. 


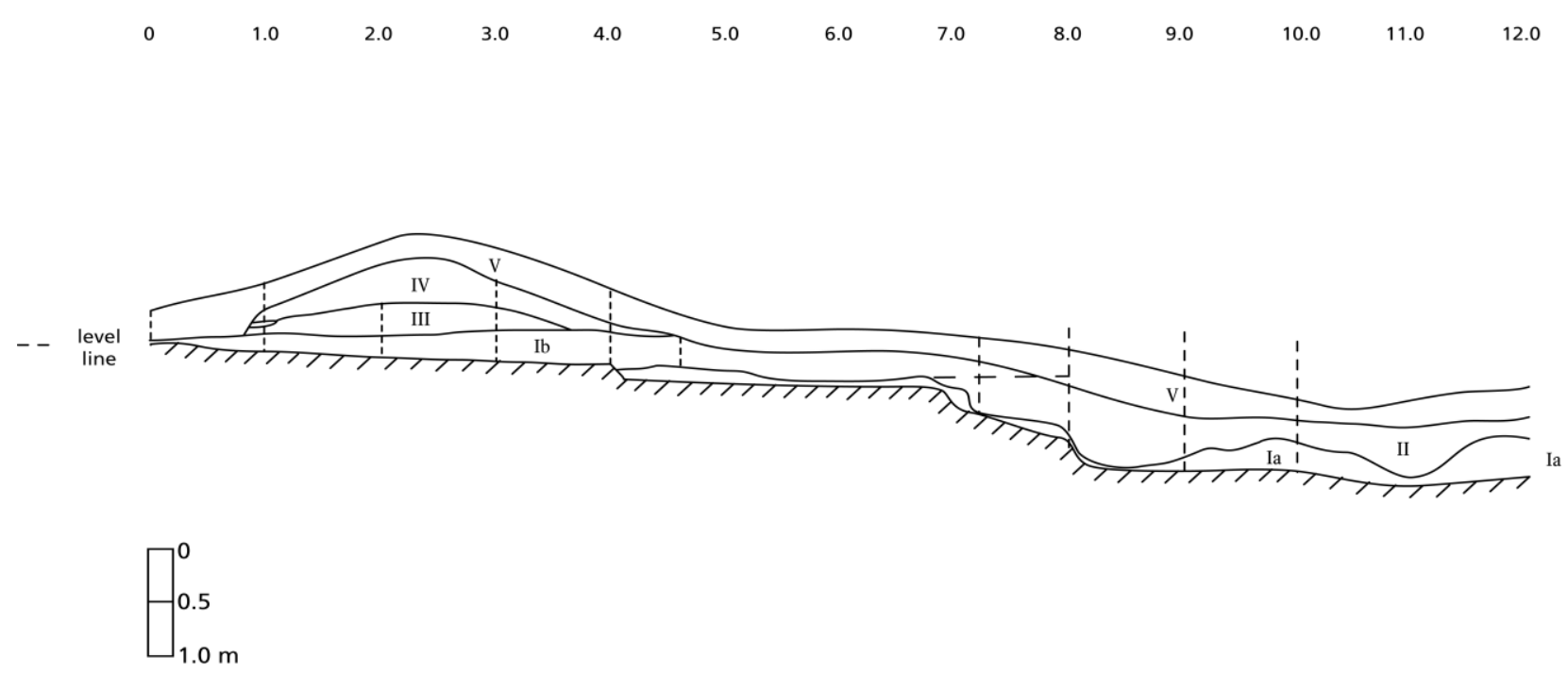

Figure 22: North wall cross section of test trench in BP1. Soil descriptions by Rolfe Mandel are shown in Table 4 (personal communication, 2011). 




Figure 23: West Wall Cross Section of Test Trench in BP2. a) West wall of the test pit dug into BP2. Rolfe Mandel's soil descriptions are shown in Table 4 (personal communication, 2011). b) Corresponding GPR line 15. White colors correspond with positive amplitudes; black colors correspond with negative amplitudes. The dip between 10 and 10.5 meters across is attributed to the gully seen in the trench. 


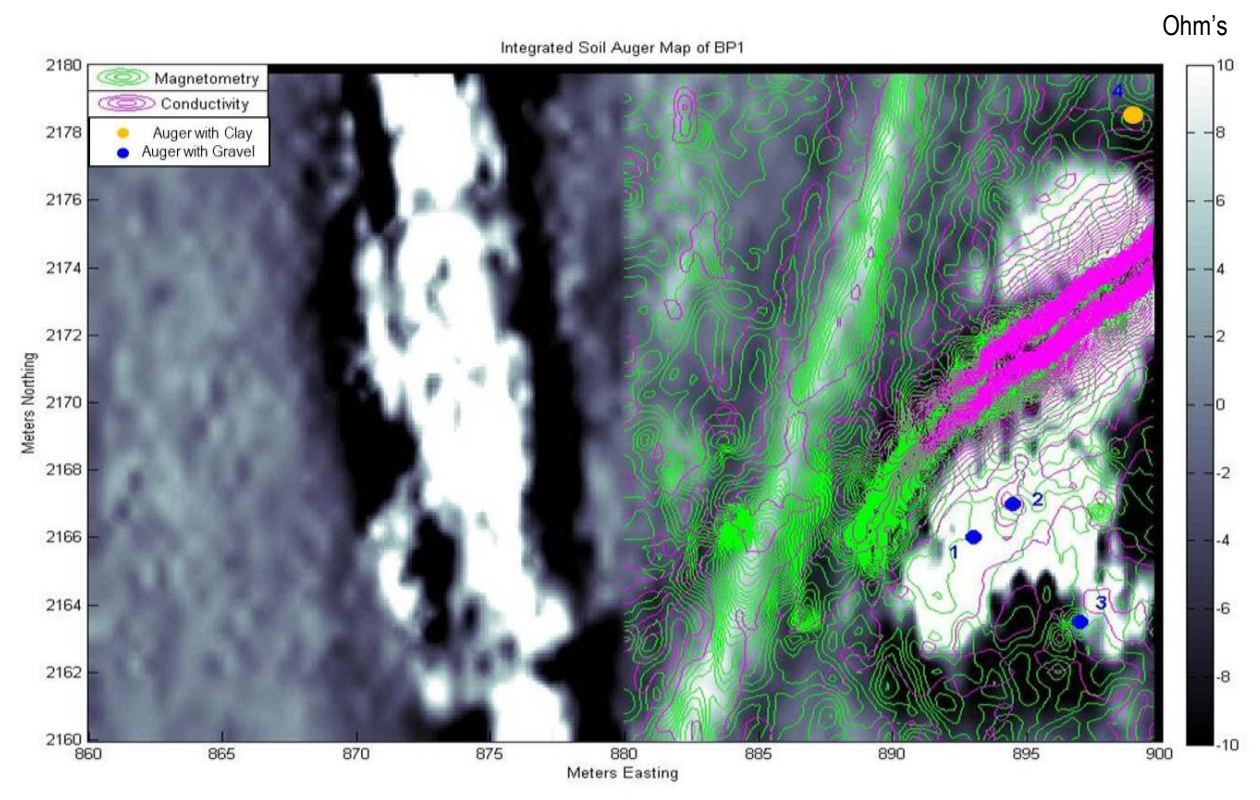

Figure 24: Integrated soil auger map of BP1 displaying resistance (grayscale), magnetic (green contours) and conductivity (purple contour) data along with the four auger locations (solid circles). The depth on this map ranges from half a meter to a meter below the surface.

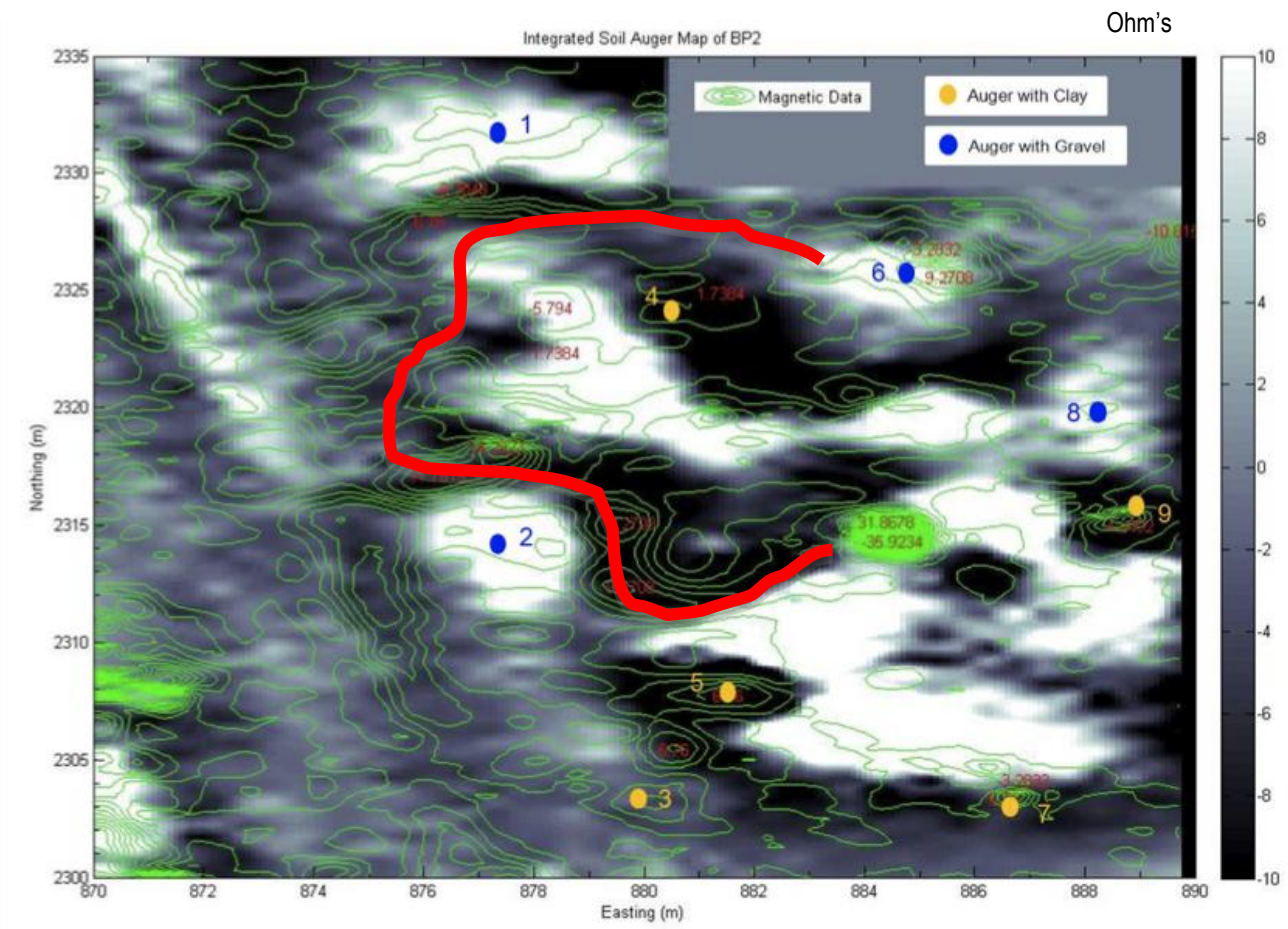

Figure 25: Integrated soil auger map of BP2 displaying resistance (grayscale) and magnetic (green contours) data along with the nine auger locations (solid circles). The red line shows the position of the circular shape seen in the magnetic data. The depth on this map is approximately $0.5 \mathrm{~m}$ below the surface. 


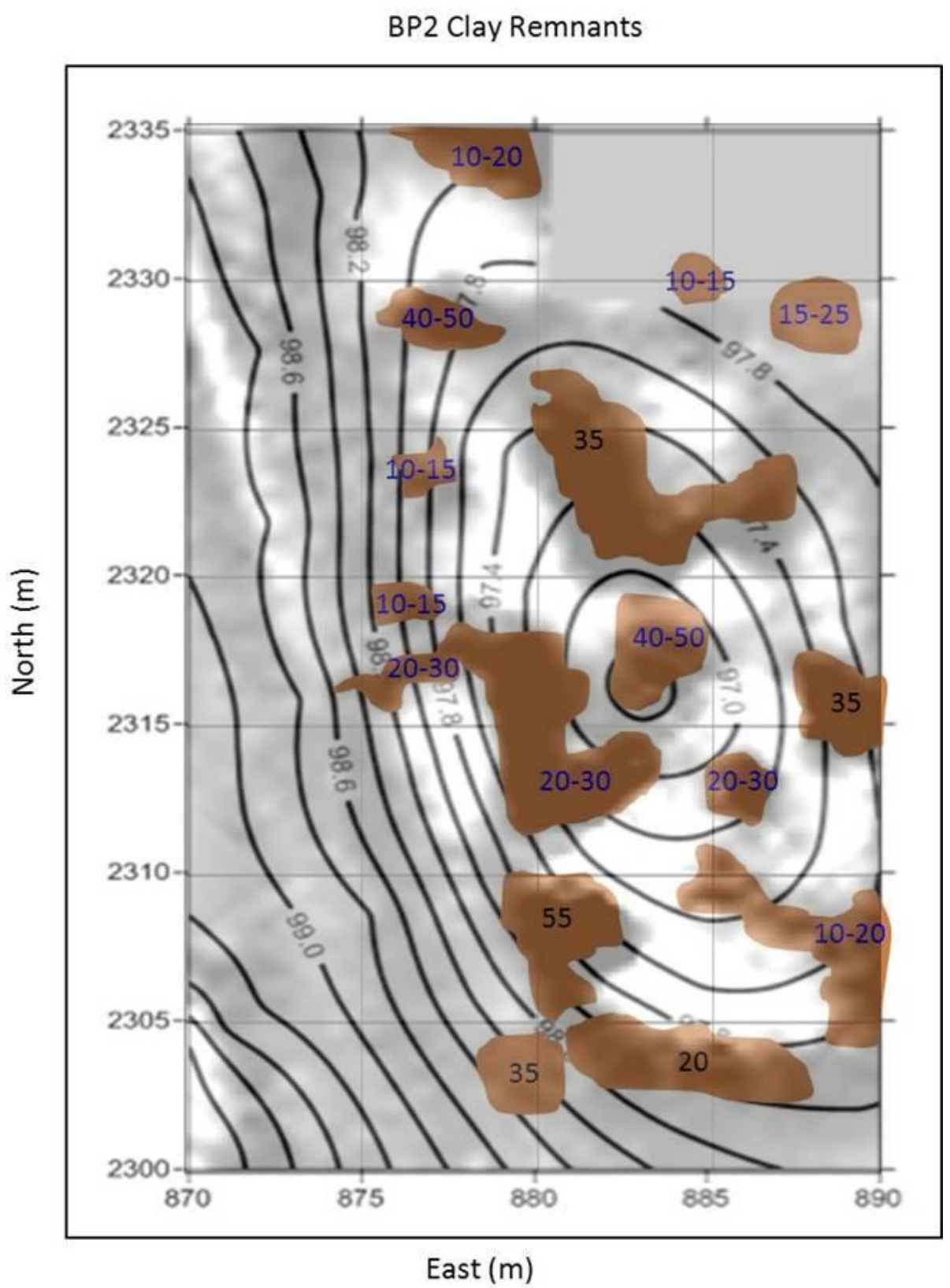

Figure 26: BP2 clay map. Contour map (m) of BP2 atop the resistance map showing the locations of the remaining clay lining with their associated thicknesses $(\mathrm{cm})$. The numbers in black are known thicknesses from the auger data. The numbers in blue are the estimated depths according to the GPR data. 


\section{Discussion}

The main objective of this study was to determine the integrity of two borrow pits at Mound City. More specifically, I tested four geophysical methods to determine how much of the clay liner emplaced in the pits by the Hopewell still remains.

The geophysical results for BP1 all show signs that the borrow pit was heavily disturbed by the construction of Camp Sherman in 1917. All four geophysical methods revealed the presence of a buried utility line that runs directly through the center of the borrow pit. This dominant feature makes it very difficult to discern subtle archeological features of interest from both the conductivity and magnetic datasets, although two areas that presented anomalies in these datasets were targeted for auguring.

The GPR data showed disturbance within the center of BP1 surrounding the location of the buried utility pipe. This is most likely due to the construction required to emplace the utility pipe, and re-excavation of the borrow pit during the 1960's. GPR was also used for correlating the 2009 trench results.

The resistance data for $\mathrm{BP} 1$ were the most promising results for identifying remnants of the clay lining, including a large area of higher resistance at the center of the borrow pit with some low resistance areas on the outer edges of the pit. These results indicate that most of the clay lining is no longer present in the center of the borrow pit, but some may still be present along the outer edges, as seen in the trench.

Auger sites 1, 2, and 3 at BP1 were all missing the clay lining. At each of these sites the topsoil is $5 \mathrm{~cm}$ thick and overlies culturally sterile sand and gravel. This finding supports the resistance data indicating that the clay lining is absent. Small anomalies in the conductivity and magnetic data were associated with auger locations 2 and 3. Nothing 
magnetic was found at location 3, but a small piece of hematite was found in auger hole 2 which may have been the cause for the weak signature in the conductivity data. Auger site 4 was in an area where, according to the resistance data, the clay liner is preserved. Again, the topsoil at this location was roughly $5 \mathrm{~cm}$ thick, but between it and the sand and gravel there was about $1 \mathrm{~cm}$ thick of the clay lining still remaining.

The geophysical results for BP2 indicate that this borrow pit has experienced much less disturbance. The resistance and GPR data proved to be the best methods for locating remnants of the clay liner, correlating very well with the trench and auguring results. Combined, the resistance and GPR data can be used to track the clay lining both vertically and horizontally across the borrow pit. Most importantly, these datasets provide evidence that the clay lining did once extend across the entire borrow pit, which supports the hypothesis that the Hopewell were attempting to maintain the structure of the pit and keep it from eroding laterally into the adjacent embankment wall.

Both magnetic datasets showed several anomalies that may represent historic and/or pre-historic features. A very high magnetic anomaly is located in the very center of the borrow pit. Previous research has shown that prehistoric features typically fall within a range of $+/-10 \mathrm{nT}$, which led to the interpretation that this anomaly is most likely historic and so an auger sample was not collected there. There does appear to be a unique shape seen in both of the magnetic datasets that is also seen in the GPR data, but the source of that shape is unknown. Auger site 6 targeted the source of this feature detected in the unique shape found in the magnetic and GPR data. Several artifacts were found, including a large amount of coal, a nail, and some bone, glass, and burnt slag. This finding is important because it demonstrates that there was some use of the borrow pit, perhaps as a disposal 
area for trash, during the Camp Sherman occupation. If the trash was scattered throughout the borrow pit, then it could explain the unique shape seen in the two datasets.

The conductivity dataset did outline general areas of lower conductivity, indicating no clay, which correlated well with the resistance and auger data. The resolution of the conductivity dataset was not as high as the resistance, which could be explained by the fact that the resistance data was acquired through direct stationary contact with the ground, whereas the conductivity meter was walked along the surface without any direct contact. The conductivity dataset is also estimated to get an average depth between 1-1.5 m below the surface, whereas the resistance datasets average depth was only $0.5 \mathrm{~m}$, providing greater detail.

Auger sites 3, 4, 5, 7, and 9 all intercepted the clay lining, but 1, 2, 6, and 8 did not. All of the auger results at BP2 correlate very well with the resistance data. BP2 was most likely affected by the reconstruction of the earthworks during the 1960s. Certain areas of the borrow pit are now missing the clay liner because re-excavation truncated it, which explains why the thickness of the remaining clay liner varies across the pit.

Auger sites 7 and 9 were targeted to determine the source of their magnetic anomalies, but nothing was found. This does not mean that magnetic objects are absent at those locations. The ground-truthing may not have covered a large enough area to find the source of the anomalies.

A test trench was excavated into the southwest borrow pit in July of 2011, where remnants of a clay lining was confirmed. This further supports the hypothesis that all eight of the borrow pits were lined. 


\section{Conclusions}

Two of the borrow pits at the Mound City Group of the Hopewell Culture National Park in Ross County, Ohio were surveyed with multiple geophysical methods and then ground-truthed with test trenches and hand augers. The goal of this research was to determine if agriculture, construction of Camp Sherman, and modern reconstruction of the earthworks have affected the integrity of these pits, specifically a clay lining that was emplaced atop the borrow pits by the Hopewell. This research also evaluated which geophysical method was most effective for answering this question.

Most of the clay lining in BP1 is absent due to the construction of Camp Sherman and the 1960s excavations, although there are still some remnants along the outer edges of the pit as detected by the geophysical, trench, and auger results. The geophysical and auger results for BP2 show that the clay lining did extend across the entire length of the borrow pit, and that after the reconstruction of the borrow pit, only half of it still remains there today.

Geophysical surveying proved to be a very effective method at Mound City. Electrical resistivity turned out to be the best method for detecting the remains of the clay lining at both borrow pits. Magnetometry and conductivity surveys worked well at identifying historic features that were buried within the borrow pits. Results of the GPR survey corroborated all of the other datasets and provided more accurate information about the location and depth of features. Combined with limited ground-truthing, these are valuable survey methods at archeological sites where invasive excavation is prohibited. 


\section{References}

Abrams, E.M., 2009, Hopewell Archaeology: A View from the Northern Woodlands: Journal of Archeological Research, v. 17, p. 169-204.

Bevan, B.W., 1998, Geophysical Exploration for Archeology: An Introduction to Geophysics Exploration: Midwest Archeological Center Special Report no. 1, p. 30

Brown, J.A., 2004, Mound City and Issues in the Developmental History of Hopewell Culture in the Ross County Area of Southern Ohio: Illinois State Museum Scientific Papers, v. 30, p. 147-168

Brown, J.A., 1994, Inventory and Integrative Analysis: Excavations at Mound City, Ross County, Ohio: Report to the National Park Service, p. 4, 135-137.

Brown, J. A. and Baby, R.S., 1966, Mound City Revisited: Unpublished report on file at the Ohio Historical Society, p. 17-19.

Burger, R.H., Sheehan, A.F., and Jones, C.H., 2006, Introduction to Applied Geophysics: Exploring the Shallow Subsurface, New York, New York, W.W. Norton \& Company, $554 \mathrm{p}$.

Burks, J., and Cook, R.A., 2011, Beyond Squier and Davis: Rediscovering Ohio's Earthworks Using Geophysical Remote Sensing: American Antiquity, v. 76, no. 4, p. 667-689.

Clay, R.B., 2001, Working With the EM38 Conductivity Meter: Geophysical Survey at the Hopeton Earthwork, Chillicothe, Ohio, May 2001: Report to the National Park Service, p. 1

Conyers, L.B., Ernenwein, E.G., Grealy, M., and Lowe, K.M., 2008, Electromagnetic Conductivity Mapping for Site Prediction in Meandering River Floodplains: Archaeological Prospection, v. 51, p. 81-91.

Conyers, L.B., and Osburn, T., 2006, GPR Mapping to Test Anthropological Hypotheses: A Study from Comb Wash, Utah, American Southwest, in Proceedings, International Conference on Ground-Penetrating Radar, $11^{\text {th }}$, Colombus: Ohio

Conyers, L.B., 2004, Ground-Penetrating Radar for Archaeology, Walnut Creek, California, Altamira Press, 203 p. 
Conyers, L. B. and Goodman, D., 1997, Ground-Penetrating Radar: An Introduction for Archaeologists, Walnut Creek, California, Altamira Press, 223 p.

Davis, J.L., and Annan, A.P., 1989, Ground-Penetrating Radar for High-Resolution Mapping of Soil and Rock Stratigraphy: Geophysical Prospecting, v. 37, p. 531-551.

De Vore, S. L., 2010, The Initial Phase of the Magnetic Investigations of the Mound City Group (32R032) at the Hopewell Culture National Historical Park, Ross County, Ohio: The Newsletter of Hopewell Archeology in the Ohio River Valley, v. 7, no. 2, p. 53-71.

Gerlitz, Kevin, Knoll, Michael D., Cross, Guy M., Luzitano, Robert D., and Knight, Rosemary, 1993, Processing Ground Penetrating Radar Data to Improve Resolution of Near-Surface Targets, in Proceedings, Symposium on the Application of Geophysics to Engineering and Environmental Problems, Volume 6, The Environmental and Engineering Society, p. 561-574.

Hanson, L. H. Jr., 1966, Excavation of the Borrow Pit, Section F, Mound City Group National Monument: Unpublished report on file at the Ohio Historical Society, p. 24.

Hardin, E.D., Lewis, K.P, and Wistendahl, W.A., 1989, Gradient Analysis of Floodplains Forests Along Three Rivers in Unglaciated Ohio: Bulletin of the Torrey Botanical Club, v. 116, no. 3, p. 258-264.

Johnson, J.K., editor, 2006, Remote Sensing in Archaeology: An Explicitly North American Perspective, Tuscaloosa, Alabama, The University of Alabama Press, $319 \mathrm{p}$.

Kvamme, K.L., 2003, Multidimensional Prospecting in North American Great Plains Village Sites: Archeological Prospection, v. 10, p. 131-142.

Lowe, K.M., and Fogel, A.S., 2010, Understanding Northeastern Plains Village Sites Through Archaeological Geophysics: Archeological Prospection, v.17, p. 247-257.

Lynott, M. and Monk, S.M., 1985, Mound City Ohio Archeological Investigations: Midwest Archeological Center Occasional Studies in Anthropology, no. 12, p. 11.

Lynott, M., Mandel, R., and Brown, J., 2010, Earthen Monument Construction at Mound City, Ohio: 2009-2010 Investigations, $56^{\text {th }}$ Annual Meeting of the Midwest Archeological Conference: Bloomington, IN 
Mills, W.C., 1922, Exploration of the Mound City Group, Ross County, Ohio: American Anthropologist, v. 27, no. 4, pg. 397-431.

Odah, H., Ismail, A., Elhemaly, I., Abbas, A., Shaaban, F., 2009, Applications of Geophysics to Archaeology: Magnetic and Ground-Penetrating Radar Investigation at Hatshepsut Temple, Luxor, Egypt, in Proceedings, Symposium on the Application of Geophysics to Engineering and Environmental Problems, 22nd, The Environmental and Engineering Society, $10 \mathrm{p}$.

Ohio Historical Society, 2005, Camp Sherman: Ohio History Central: http://www.ohiohistorycentral.org/entry.php?rec=670 (October 2010) Rapp, G.R., and Hill, C.L., 2006, Geoarchaeology: The Earth Science Approach to Archaeological Interpretation, New Haven, Connecticut, Yale University Press, $2^{\text {nd }}$ edition, $339 \mathrm{p}$.

Stierman, D.J., and Brady, J.E., 1999, Electrical Resistivity Mapping of Landscape Modifications at the Talgua Site, Olancho, Honduras: Geoarchaeology: An International Journal, v. 14, no. 6, p. 495-510.

Squier, E.G., and Davis, E. H., 1848, Ancient Monuments of the Mississippi Valley, Smithsonian Institute Press, Washington D.C.

Thornberry-Ehrlich, T.L., 2010, Geologic Resources Inventory Scoping Summary Hopewell Culture National Historical Park, Ohio: Geologic Resources Division, National Park Service, $18 \mathrm{p}$.

Ward, Stanley H., editor, 1990, Geotechnical and Environmental Geophysics: Tulsa, Oklahoma, Society of Exploration Geophysicists, Investigations in Geophysics, v. 1, no. 5, p. 75-190.

Whittaker, William E., and Storey, Glenn R., 2008, Ground-Penetrating Radar Survey of the Sny Magill Mound Group, Effigy Mounds National Monument, Iowa: Geoarchaeology: An International Journal, v. 23, no. 4, p. 479-499. 
Appendix A 
BP1-1, 893 E: $2166 N$

Depth

Soil

$(\mathrm{cm})$

0-5

Description

Topsoil

5-25

10YR 4/4 dark yellowish brown. Loose, crumbly sand and gravel.

Geophysical Comparison: Area of higher resistance, indicating no clay lining present as found.

BP1-2, 894.5 E: $2167 \mathrm{~N}$

Depth

Soil

(cm)

0-5

Description

Topsoil

5-20

10YR 4/4 dark yellowish brown. Loose, crumbly sand and gravel. A piece of hematite was found in this horizon.

Geophysical Comparison: Area of higher resistance and a small conductivity anomaly. No clay lining was found which correlates with the resistance data, and the hematite found may be the cause of the conductivity anomaly.

BP1-3, 897 E: $2163.5 \mathrm{~N}$

Depth Soil

(cm) Description

0-5 Topsoil

5-30 10YR 4/4 dark yellowish brown. Loose, crumbly sand and gravel.

Geophysical Comparison: Area of higher resistance and a magnetic anomaly. No clay lining was found which correlates with the resistance data.

BP1-4, 899 E: $2178.5 \mathrm{~N}$

Depth

$(\mathrm{cm})$

$0-5$

Soil

Description

Topsoil

$5-25$

10YR 3/4 dark yellowish brown. A-Horizon loam fill. Very crumbly, with organic matter and gravel present. Two prehistoric flakes were found in this horizon. 
10YR 4/4 dark yellowish brown. Loose, crumbly sand and gravel. There was a very thin line ( $<1 \mathrm{~cm}$ thick) of a reddish clay directly atop this horizon, but it was too thin to be certain that it was a different horizon.

Geophysical Comparison: Area of slightly lower resistance and a magnetic anomaly. A very thin remnant of the clay lining may be present here.

BP2-1, 877.5 E: $2314 \mathrm{~N}$

Depth

$(\mathrm{cm})$

$0-3$

3-25

$25-54$
Soil

Description

Topsoil

10YR 3/3 dark brown. Silty loam fill containing gastropods and mollusk shells, as well as gravel and some organic material. Sample 1 taken from this layer.

10YR 4/4 dark yellowish brown. Loose, crumbly sand and gravel. Sample 2 taken from this layer.

Geophysical Comparison: High resistance area indicated no clay lining as found.

BP2-2, 877.5 E: $2332 \mathrm{~N}$

Depth

$(\mathrm{cm})$

$0-3$

3-35

$35-50$
Soil

Description

Topsoil

Geophysical Comparison: High resistance area indicated no clay lining as found.

BP2-3, 880 E: $2303.5 \mathrm{~N}$

Depth

$\underline{(\mathrm{cm})}$

$0-3$
10YR $2 / 2$ very dark brown. Silty clay loam, containing large gravel chunks. Sample 3 taken from this layer.

10YR 4/4 dark yellowish brown. Loose, crumbly sand and gravel.
Soil

Description

Topsoil 
10YR 3/3 dark brown. Clay loam containing gastropod and mollusk shells, gravel, and organic material.

20-55

7.5 YR 4/6 strong brown. Sandy gravel clay that is much more reddish in color. One prehistoric flake was found in this unit. Sample 4 taken from this layer.

$55-62$

10YR 4/4 dark yellowish brown. Loose, crumbly sand and gravel.

Geophysical Comparison: High amplitude anomaly noted in the GPR data, but the modern trail created noise in the other datasets. Clay lining was found.

BP2-4, 880.5 E: $2324 \mathrm{~N}$

Depth Soil

(cm) Description

0-3 Topsoil

3-35 10YR 3/3 dark brown. Silty clay loam containing gastropods and mollusk shells, gravel, and organic material.

35-70 7.5 YR 4/6 strong brown. Sandy gravel clay that is much more reddish in color. Sample 5 taken in this unit.

70-75 10YR 4/4 dark yellowish brown. Loose, crumbly sand and gravel.

Geophysical Comparison: Low resistance area indicating a clay lining present as found.

BP2-5, 881.5 E: $2308 \mathrm{~N}$

Depth Soil

(cm) Description

0-3 Topsoil

3-22 10YR 3/2 very dark grayish brown. Silty clay loam containing gastropods and mollusk shells, gravel, and organic material. Samples 1-4 were collected in sunlight, and samples 5-9 were collected in the shade, which may be the cause of the slight color change here.

$22-75$

7.5 YR 4/6 strong brown. Sandy gravel clay that is much more reddish in color.

76-80 10YR 4/4 dark yellowish brown. Loose, crumbly sand and gravel.

Geophysical Comparison: Low resistance area indicating a clay lining present as found. 
BP2-6, 884.5 E: $2325.5 \mathrm{~N}$

*Moved from original location half a meter to the south because of a tree root that prevented auguring.

Depth

$(\mathrm{cm})$

$0-3$

Soil

Description

Topsoil

3-45

10YR 3/2 very dark grayish brown. Silty loam. Beginning at $25-27 \mathrm{~cm}$ bs an abundance of coal began to appear. Hit a line of large fist-sized rocks at $30 \mathrm{~cm}$ bs that extended down to $40 \mathrm{~cm}$ bs. At $40 \mathrm{~cm}$ bs a large brick was found. Between $25-45 \mathrm{~cm}$ bs coal, glass, bone, nail and slag were found.

$45-65$

10YR 3/6 dark yellowish brown. Loose, crumbly sand and gravel, feels more moist. Sample 6 taken from this unit.

Geophysical Comparisons: Anomaly noted in GPR data most likely corresponds to buried tree root. Magnetic anomaly correlates well with the coal and nails found. High resistance area indicative of no clay lining present, as found.

BP2-7, 886.5 E: $2303 \mathrm{~N}$

*This location was moved due a tree root that prevented auguring in original spot Depth Soil

(cm)

$0-3$ Description

Topsoil

$3-21$

10YR 3/2 very dark grayish brown. Silty clay loam with gastropods and mollusks, root material, and gravel noted.

$21-40$

7.5 YR 4/6 strong brown. Sandy gravel loam, much more moist and sticky here than at other locations.

$40-46$

10YR 4/4 dark yellowish brown. Loose, crumbly sand and gravel.

Geophysical Comparisons: Magnetic are of interest and slightly lower resistance. No magnetic features noted but clay lining was found.

BP2-8, 888 E: $2320 \mathrm{~N}$

Depth

$(\mathrm{cm})$

$0-3$

$3-30$
Soil

Description

Topsoil

10YR 3/2 very dark grayish brown. Silty loam containing gastropods and mollusk shells, as well as gravel and roots. 
10YR 4/4 dark yellowish brown. Loose, crumbly sand and gravel. Found what may be a very thin remnant $(<1 \mathrm{~cm}$ thick) of the clay lining in this unit, but too thin to be certain.

Geophysical Comparisons: High resistance area indicated no clay lining, as found.

BP2-9, 888.5 E: $2315.5 \mathrm{~N}$

Depth

Soil

(cm)

$0-3$

Description

Topsoil

3-21

10YR 3/3 dark brown. Silty loam that contains gastropods and mollusk shells, and some gravel is present. One piece of glass was found between 13-20 cm bs.

21-55

7.5YR 4/6 strong brown. Sandy gravel clay, but had noticeably lower clay content than the other locations where it was found present. Sample 7 taken from this unit.

$55-60$

10YR 4/4 dark yellowish brown. Loose, crumbly sand and gravel.

Geophysical Comparisons: Low resistance area that indicated a clay lining was present, as found. 